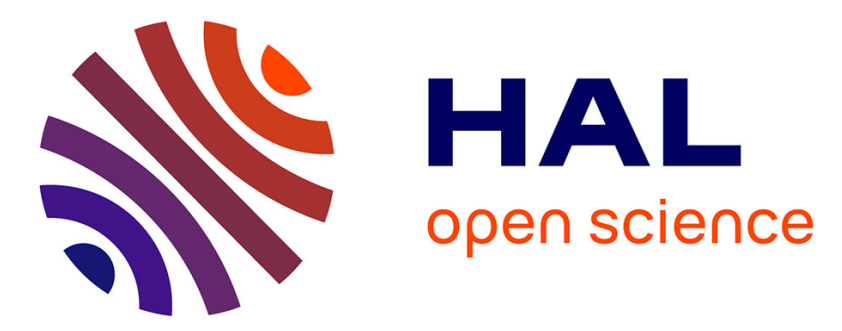

\title{
In situ EBSD investigation of deformation processes and strain partitioning in bi-modal Ti-6Al-4V using lattice rotations
}

\author{
S. Hémery, P. Villechaise
}

\section{- To cite this version:}

S. Hémery, P. Villechaise. In situ EBSD investigation of deformation processes and strain partitioning in bi-modal Ti-6Al-4V using lattice rotations. Acta Materialia, 2019, 171, pp.261-274. 10.1016/j.actamat.2019.04.033 . hal-02166762

\section{HAL Id: hal-02166762 \\ https://hal.science/hal-02166762}

Submitted on 22 Oct 2021

HAL is a multi-disciplinary open access archive for the deposit and dissemination of scientific research documents, whether they are published or not. The documents may come from teaching and research institutions in France or abroad, or from public or private research centers.
L'archive ouverte pluridisciplinaire HAL, est destinée au dépôt et à la diffusion de documents scientifiques de niveau recherche, publiés ou non, émanant des établissements d'enseignement et de recherche français ou étrangers, des laboratoires publics ou privés.

\section{(ㄷ)(1) $\$$}

Distributed under a Creative Commons Attribution - NonCommerciall 4.0 International 


\title{
In situ EBSD investigation of deformation processes and strain partitioning in bi-modal Ti-6Al-4V using lattice rotations
}

\author{
S. Hémery ${ }^{1 *}$, P. Villechaise ${ }^{1}$ \\ ${ }^{1}$ Institut Pprime, CNRS - ISAE-ENSMA - Université de Poitiers, UPR CNRS 3346, Physics and Mechanics of \\ Materials Department, ENSMA - Téléport 2, 1 avenue Clément Ader, BP 40109, 86961 Futuroscope Chasseneuil \\ Cedex, France \\ * Corresponding author: samuel.hemery@ensma.fr
}

\section{$\underline{\text { Abstract }}$}

Identification of operating deformation processes and assessment of the resulting strain partitioning are critical concerns for mechanical properties prediction and microstructure optimization in complex alloys such as $\alpha / \beta$ titanium alloys. Lattice rotation relative to the initial orientation was presently used as a marker of slip activity. A Ti-6Al-4V specimen with a bi-modal microstructure was tested in tension in a scanning electron microscope. Crystallographic orientations were characterized in situ using electron back-scattered diffraction (EBSD). A successful prediction of activated slip systems was achieved using the rotation axis associated with plastic activity. The combination of this procedure and slip traces analysis offers an insight into the determination of both slip plane and slip direction of active slip systems. Based on classical crystal plasticity formulations, the magnitude of the rotation relative to the initial orientation was interpreted in terms of plastic shear magnitude. A quantitative assessment of plastic strain at the microstructure scale was then carried out using lattice rotation data. This approach enabled to discuss strain partitioning in Ti-6Al-4V considering the influence of microstructural features and active slip modes.

\section{Graphical abstract:}

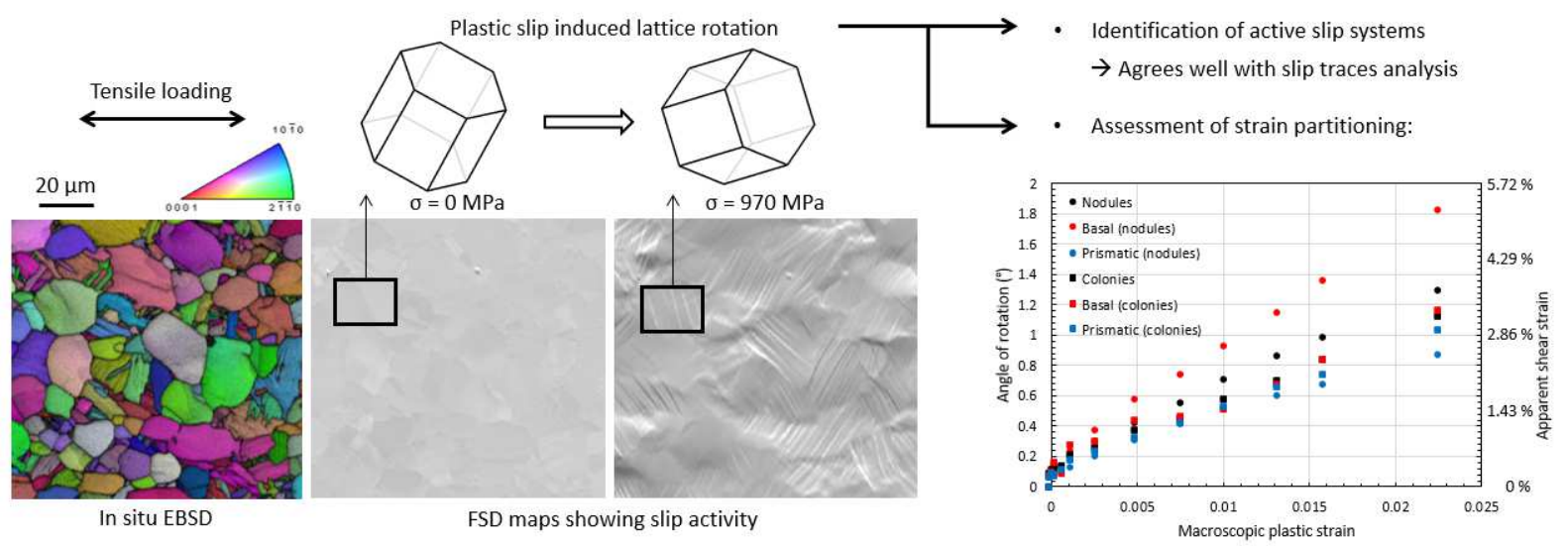

Keywords: Titanium alloys; EBSD; Slip; Grain rotation; Strain distribution

\section{Introduction}

$\alpha / \beta$ titanium alloys are widely employed in the aerospace industry owing to superior mechanical properties. In particular, bi-modal microstructures composed of equiaxed primary $\alpha$ nodules and colonies of secondary $\alpha$ lamellas embedded in the $\beta$ matrix are extensively employed. 
This duplex microstructure combines the advantages of equiaxed and lamellar structures for a wellbalanced property profile [1]. The thermo-mechanical processing route determines the microstructural features [2]. In-service properties notably depend on (i) $\alpha$ precipitates arrangements, morphologies, sizes and associated volume fractions [3,4], (ii) crystallographic textures [5,6] and (iii) elemental partitioning, short-range ordering and $\alpha_{2}$ precipitation $[7,8]$. Tailoring of microstructure for optimum performance is looked for through a thorough understanding of the operative deformation and damage processes in relation with microstructural characteristics.

The duplex microstructure of titanium alloys induces a heterogeneous plastic deformation behavior. According to in situ scanning electron microscopy observations of tensile deformation, the early slip activity proceeds in nodules [9-13]. In order to obtain a good match between crystal plasticity simulations and experimental observations, a higher critical resolved shear stress value is usually assigned to colonies, which testifies of a delayed slip activity in transformed $\beta$ regions $[14,15]$. This spatially heterogeneous character is amplified by the intrinsic plastic anisotropy of the hexagonal close-packed $\alpha$ phase. Different strengths were reported for the various families of slip systems [16-18]. While basal and prismatic slip strengths, which have been recently reviewed in [4], are similar, the pyramidal slip strength is significantly higher. However, only the latter mode can accommodate the c-axis deformation of the hexagonal close-packed lattice. As a result, the overall response of titanium alloys is governed by stress and strain partitioning, which has been identified as a key phenomenon under monotonic tension, fatigue or dwell-fatigue loadings for instance $[17,19$ 21]. However, experimental data including a quantitative assessment of the heterogeneities are still scarce.

Electron backscatter diffraction (EBSD) is a common laboratory based tool used to measure crystal orientations from crystalline samples [22]. Various EBSD based procedures have been proposed to analyze plastic strain at the microstructure scale $[23,24]$. Degradation of the diffraction patterns in strained materials was first used as an indication of the distribution of strain [25]. Alternatively, a local misorientation based approach, which relies on the variation of crystal orientation within a grain, was introduced as strain estimation procedure [26-28]. Local plastic deformation processes were also studied using the lattice rotation relative to its initial orientation. The rotation path was found characteristic of activated slip systems [29-31]. Although no strain quantification was attempted, a prior study reported a linear relationship between macroscopic plastic strain and lattice rotation using X-ray diffraction [29,32]. Analytically, the rate of reorientation of the crystal axes $\boldsymbol{W}^{*}$ is decomposed as follows [33]:

$\boldsymbol{W}^{*}=\boldsymbol{W}^{g}-\boldsymbol{W}^{c}$

With $\boldsymbol{W}^{g}$ the 'rigid -body spin' describing the grain shape rotation relative to a reference frame and $\boldsymbol{W}^{c}$ the plastic spin describing the differential rotation of the samples axes of a grain in terms of its crystallographic axis. Individual assessment of both rotation components is experimentally challenging. $\boldsymbol{W}^{g}$ can be decomposed into a component accounting for the sample rotation relative to the reference frame and a component relative to the grain shape rotation relative to the sample frame. The contribution of the former component can be limited through carefully controlled test conditions. For instance, in situ testing limits specimen positioning error at each deformation step. Material homogeneity at the specimen scale is also an important factor. The latter component, accounting for grain shape rotation relative to the sample frame, is the consequence of the deformation of surroundings. This effect, which is also difficult to evaluate, could be dismissed using a statistical approach. The effect of deforming neighbors should compensate provided multiple grains are considered. Finally, $\boldsymbol{W}^{c}$ is expressed for an elementary volume in most crystal plasticity models using equation (2) [33]: 
$\boldsymbol{W}^{c}=\sum_{i=1}^{N} \frac{1}{2}\left(\boldsymbol{s}_{\boldsymbol{i}} \otimes \boldsymbol{m}_{\boldsymbol{i}}-\boldsymbol{m}_{\boldsymbol{i}} \otimes \boldsymbol{s}_{\boldsymbol{i}}\right) \dot{\gamma}_{i}$

With $\dot{\gamma}_{i}$ the slip rate, $\boldsymbol{s}_{\boldsymbol{i}}$ the slip plane in the sample frame and $\boldsymbol{m}_{\boldsymbol{i}}$ the slip direction in the sample frame associated with slip system $i$. If a single slip system is active, the following remarks can be made using equation (2). Firstly, the axis of the lattice rotation rate is characteristic of the activated slip system. Secondly, the predicted lattice rotation rate magnitude is directly proportional to the plastic shear rate. Therefore, a straightforward relation between experimentally measured lattice rotation and plastic shear can be found if appropriate test conditions and procedures are applied. The present work is based on this analysis.

In this article, we introduce a novel approach to study plastic deformation and strain partitioning based on in situ electron back-scattered diffraction (EBSD) characterization of lattice rotation during a tensile test. The lattice rotation relative to the initial orientation is used as a source of information on deformation behavior at the grain scale. A procedure for active slip system identification is first proposed and discussed regarding slip traces analysis as a reference procedure. The relation between plastic strain and lattice rotation in terms of magnitude is then discussed based on experimental data and analytical calculations. This analysis is finally used to assess the respective influence of microstructural features and active slip modes on strain partitioning. Improvements in the understanding and modeling of deformation of bi-modal Ti-6Al-4V are discussed.

\section{Experimental}

Ti-6Al-4V with a bimodal microstructure composed of equiaxed primary $\alpha$ nodules and secondary $\alpha$ lamellas embedded in the $\beta$ matrix is used in the present study. According to EBSD analysis, primary $\alpha$ nodules with an average diameter of $12 \mu \mathrm{m}$ account for $54 \%$ of the specimen surface. The microstructure and the local crystallographic orientations in the region followed in situ are presented in figure $1 \mathrm{a}$. In this alloy, the $\beta$ phase is associated with a low surface fraction [9]. As a consequence, only $\alpha$ phase was considered. 34 primary $\alpha$ nodules and 21 lamellar colonies were selected for the present investigations. The nodules exhibit an average diameter of about $12 \mu \mathrm{m}$. The set of colonies was built to obtain a similar average diameter. The grain averaged crystallographic orientations are plotted on an inverse pole figure in figure $1 \mathrm{~b}$ and $1 \mathrm{c}$ for the 34 nodules and the 21 colonies respectively. The crystallographic orientations are fairly well distributed over the whole orientation domain for both nodules and colonies. Since the different slip modes are favored in distinct crystallographic orientation domains [9], a similar distribution of basal and prismatic slip modes is expected for both nodules and colonies. 

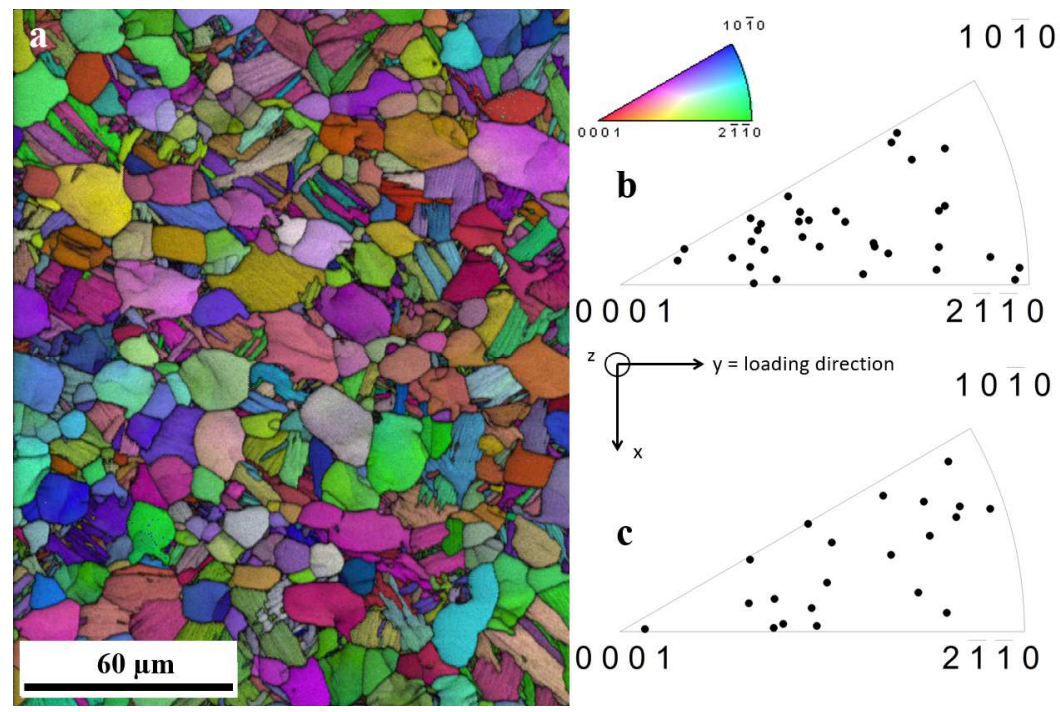

Figure 1. a. Image quality and inverse pole figure along the loading direction showing the microstructure and the crystallographic orientation in the region of interest (the loading direction is horizontal), b. and c. inverse pole figure plots showing the average crystallographic orientations of nodules and colonies considered in the present study

An in situ tensile test was carried out using a Deben tensile stage with a $2 \mathrm{kN}$ loadcell in a JEOL 6100 scanning electron microscope (SEM) equipped with an EBSD setup provided by EDAX. A $0.8 \mathrm{~mm}$ thick dogbone shaped specimen with a gage length of $10 \mathrm{~mm}$ and a gage width of $2 \mathrm{~mm}$ was used. After grinding both faces up to 4000 grade SiC paper, two additional polishing steps were applied on one face. Rough polishing was carried out using a solution containing $9 \mu \mathrm{m}$ diamond particles. A final polishing step was applied using a mixture of colloidal silica suspension with a mean particle size of $0.04 \mu \mathrm{m}$ and $10 \% \mathrm{H}_{2} \mathrm{O}_{2}$. Incremental loading of the specimen was performed using a displacement rate of $0.02 \mathrm{~mm} \mathrm{~min}^{-1}$. The crosshead displacement is measured using a linear variable differential transformer position transducer. The engineering strain is derived from the displacement data after a machine stiffness correction using a reference Young's modulus of $115 \mathrm{GPa}$. In order to characterize the surface of the specimen at different deformation stages, the crosshead displacement was stopped after reaching targeted stress values. The engineering stress - strain conditions corresponding to arrests of the crosshead displacement are plotted on figure 2a. The characterization of the crystallographic orientations in the region of interest was performed at each stop using EBSD. The microscope is operated under a $25 \mathrm{kV}$ tension and a probe current of about 5 $\mathrm{nA}$ is used. Kikkuchi diffraction patterns are acquired with a $5 \times 5$ binning ( $128 \times 96$ pixels) and indexed using a standard Hough transform-based automated processing at a rate of 200 points per second. A $0.4 \mu \mathrm{m}$ hexagonal step was applied for a scan duration of 30 minutes at each loading step. 

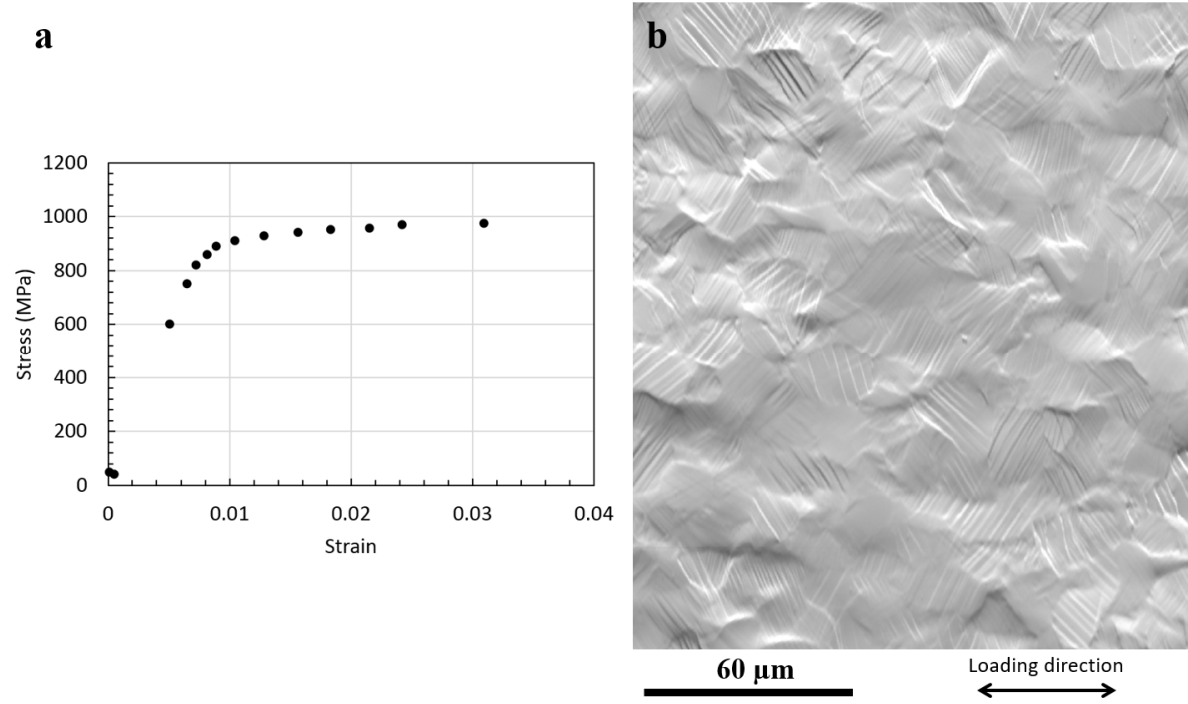

Figure 2. a. Engineering stress - strain conditions at which EBSD mapping of the region of interest was performed and b. FSD map at the $970 \mathrm{MPa}$ step showing slip traces and surface roughness indicative of plastic deformation

Operating deformation systems were first identified using a slip traces analysis at each loading step. Forward-scattered electron (FSD) micrographs are used for the slip trace detection. A FSD map of the region of interest at the $970 \mathrm{MPa}$ step is shown in figure $2 \mathrm{~b}$. The orientation of experimental and theoretical slip traces as calculated using the EBSD data are compared. $\{0001\}$, $\{10 \overline{1} 0\}$ and $\{10 \overline{1} 1\}$ slip planes are presently considered. Since <c+a>-type pyramidal slip is associated with a higher slip strength than <a>-type pyramidal slip, only <a>-type slip was considered in the following [16-18]. A $5^{\circ}$ criterion was used to assign experimental slip traces to matching basal, prismatic or pyramidal slip planes. The slip direction has to be inferred with this approach. The activated prismatic or pyramidal slip systems were directly deduced owing to the one-to-one slip direction / slip plane match. However, the basal plane is associated with three different slip directions. Prior studies reported a proper description of slip activation in Ti-6Al-4V using Schmid's law [9]. Accordingly, the basal slip system with the highest Schmid factor is assumed to be activated. Multiple - or no - matching slip planes resulted in a dismissed analysis unless all the matching systems but one exhibit very low Schmid factors $(<0.25)$. Indeed, activation of a slip system with a Schmid factor lower than 0.25 is very unlikely [9,34-36]. An apparent critical resolved shear stress (CRSS) value was estimated for each successful basal or prismatic slip system identification. Assuming a global stress state, the apparent CRSS value was calculated as the product of the Schmid factor and the average of the remote stress applied before and after slip trace appearance. Apparent CRSS values and associated standard deviations were finally averaged over both basal and prismatic slip systems. This procedure, which relies on a homogeneous stress assumption, neglects stress heterogeneities. However, a prior study revealed that the bias introduced is limited if a statistical approach is applied [37].

In order to study lattice rotations at the nodule / colony scale, pre-processing of the raw crystallographic orientation data was performed using OIM analysis software. The following steps are applied. (i) Data points with a confidence index below 0.1 were dismissed in order to rule out unreliable data points. (ii) Separate nodules / colonies were identified using a $2^{\circ}$ misorientation criterion. (iii) The average crystallographic orientations of the 34 nodules and the 21 colonies considered in the present study were computed. The resulting Euler angles $\left(\varphi_{1}, \Phi, \varphi_{2}\right)$ were then processed using an in-house Matlab code in order to calculate the lattice rotation relative to the 
initial lattice orientation. The crystalline orientation at step $i$ is expressed in the specimen frame using the rotation matrix $\boldsymbol{R}_{\mathbf{0}, \boldsymbol{i}}$ defined as follows (3).

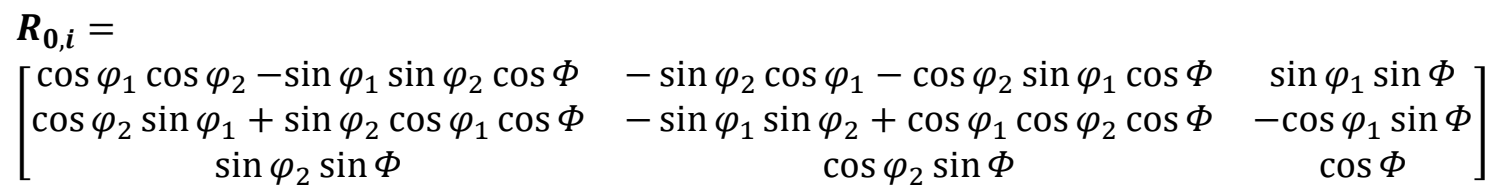

The lattice rotation between step $j$ and step $i$ is described using the rotation matrix $\Delta \boldsymbol{R}_{i, j}$ given in equation (4).

$$
\Delta R_{i, j}=R_{0, j} R_{0, i}^{-1}
$$

The magnitude of the rotation, which is denoted as $\theta_{i, j}$, is computed using equation (5).

$\theta_{i, j}=\cos ^{-1}\left(\frac{\Delta R_{i, j 11}+\Delta R_{i, j 22}+\Delta R_{i, j 33}-1}{2}\right)$

Single slip in a constrained crystal is accompanied by lattice rotation. According to equation (2), the associated rotation axis under single slip condition is normal to both the slip plane normal and the slip direction. This axis is denoted in the following as the slip-induced rotation axis. The slip plane normals $\vec{n}_{i, s}$ and the slip directions $\overrightarrow{m_{l, S}}$ are expressed in the specimen frame for the slip system $s$ at each loading step $i$ according to equations (6) and (7).

$\vec{n}_{i, s}=\boldsymbol{R}_{\mathbf{0}, \boldsymbol{i}} \cdot \vec{n}_{0, s}$

$\vec{m}_{i, s}=\boldsymbol{R}_{\mathbf{0}, i} \cdot \vec{m}_{0, s}$

The normal to both slip plane normal and slip direction (i.e. the slip induced rotation axis) for each slip system is then calculated using equation (8).

$\overrightarrow{t_{l, S}}=\vec{n}_{i, s} \wedge \overrightarrow{m_{l, S}}$

Prior works reported that $\langle\mathrm{a}\rangle$ or $\langle\mathrm{c}+\mathrm{a}\rangle$ pyramidal slip is associated with rare observations $[9,10]$. In the present work, only basal and prismatic slip systems are considered in order to simply the prediction of operating slip systems owing to a reduced number of potential slip induced rotation axes. Each basal slip system leads to a distinct rotation axis whereas prismatic slip is associated with a single rotation axis for any considered slip system. The magnitude of the rotation between loading steps $i$ and $j$ was computed for the 4 slip induced rotation axis. Assuming a negligible rigid body rotation of the grain, the magnitude of the rotation should be the lowest for the operating slip system.

The angle of the rotation from $\overrightarrow{t_{l, S}}$ to $\overrightarrow{t_{j, S}}$, which is denoted as $\alpha_{i, j, s}$, is calculated for each slip system $s$ using equation (9).

$$
\alpha_{i, j, s}=\cos ^{-1}\left(\left\langle\overrightarrow{t_{l, s}}, \overrightarrow{t_{j, s}}\right\rangle\right)
$$

This approach implicitly implies that only single slip can be properly considered. Hence, the tensile test was stopped after $3 \%$ total strain in order to avoid frequent multiple slip occurrences. Similarly, cross-slip may also induce deviations of the theoretical slip induced rotation axis. This latter point can be dismissed in the present conditions since cross-slip is inhibited in titanium alloys with a high aluminum content owing to planar slip [8]. 
A reliable prediction of the operating slip system also requires an accurate determination of the slip induced rotation axis. However, a prior study based on individual orientation measurement using EBSD reported that the misorientation axis is essentially undetermined for an applied rotation of $5^{\circ}$, or less. In the present work, instead of using individual measurements, the measurements are averaged over more than 500 points. Compared to single measurements, the resulting orientation has a significantly improved precision. The standard deviation of the average orientation $\operatorname{std}(\bar{\theta})$ is given below as a function of $\operatorname{std}(\theta)$ the standard deviation of individual measurements and $N$ the number of measurements used for the average.

$$
\operatorname{std}(\bar{\theta})=\frac{\operatorname{std}(\theta)}{\sqrt{N}}
$$

The standard deviation in the orientation calculation is then reduced by a factor higher than 20. A correct prediction of the slip induced rotation axis is demonstrated in Appendix 1 for rotation magnitudes as low as $0.1^{\circ}$. However, other effects, such as rigid -body rotations or free surface related effects, could influence the results. This is discussed in the following sections.

The slip induced rotation axis being widely employed in the following, it is referred to as SIR axis. In addition, the angle of rotation being systematically discussed relatively to the initial orientation, it is simply denoted as angle of rotation.

\section{3. $\quad$ Results}

\subsection{Slip trace analysis}

Slip traces were observed on the surface of 32 nodules among 34 nodules considered. A slip traces analysis was performed in order to identify the activated slip systems in these nodules. The applied stress at which the slip trace was detected, the operating slip mode and the apparent CRSS are reported in table 1 for each nodule. The first basal slip trace was observed at the $785 \mathrm{MPa}$ step while the first prismatic slip band was observed at the $840 \mathrm{MPa}$ step. According to this observation, the activation of basal slip proceeds at a lower macroscopic stress magnitude than the activation of prismatic slip. The same activation kinetics have been reported for Ti-6Al-4V and other titanium alloys with similar aluminum contents [10-12]. Observations of pyramidal slip are occasional (3 occurrences out of 34 nodules). Hence, this slip system can reasonably be excluded from the analysis of deformation processes using lattice rotations. The average apparent CRSS is about 364 MPa for basal slip versus about $375 \mathrm{MPa}$ for prismatic slip. These values are consistent with estimates reported in prior studies [36]. The basal / prismatic CRSS ratio is about 0.97 which is also in good agreement with previous results. The standard deviations of basal and prismatic CRSS values are 55 $\mathrm{MPa}$ and $37 \mathrm{MPa}$ respectively. Standard deviations extracted from prior studies focusing on similar titanium alloys are in the $20 \mathrm{MPa}-40 \mathrm{MPa}$ range [10-12,37]. The present values are thus slightly higher than the ones previously reported. This observation is most likely related to the rough description of slip activation kinetics. Indeed, a low number of stops was performed in the stress range below the $0.2 \%$ proof stress, in which a gradual activation of basal and prismatic slip systems is observed [10]. Slip traces analysis is usually based on secondary electron micrographs or backscattered electron micrographs. Interestingly, consistent results were obtained using FSD micrographs, which were taken on a $70^{\circ}$ tilted specimen.

\begin{tabular}{ccccc}
\hline Nodule $\mathrm{N}^{\circ}$ & $\begin{array}{c}\text { Applied stress at } \\
\text { slip trace } \\
\text { detection (MPa) }\end{array}$ & $\begin{array}{c}\text { Activated slip } \\
\text { system according to } \\
\text { slip trace analysis }\end{array}$ & $\begin{array}{c}\text { Apparent } \\
\text { CRSS }\end{array}$ & Remark \\
\hline Nodule 1 & 785 & Basal & 361.1
\end{tabular}




\begin{tabular}{|c|c|c|c|c|}
\hline Nodule 2 & 900 & Basal & 232.6 & \\
\hline Nodule 3 & 840 & Pyramidal & 333.9 & \\
\hline Nodule 4 & 875 & Basal & 436.8 & \\
\hline Nodule 5 & 840 & Basal & 394.4 & \\
\hline Nodule 6 & 785 & Basal & 378.8 & \\
\hline Nodule 7 & 935 & Prismatic & 283.7 & \\
\hline Nodule 8 & 920 & & & Unidentified - No matching slip trace \\
\hline Nodule 9 & 920 & Basal & 266.8 & \\
\hline Nodule 10 & 840 & Basal & 373.5 & \\
\hline Nodule 11 & 840 & Basal & 364.5 & \\
\hline Nodule 12 & 875 & Prismatic & 363.1 & \\
\hline Nodule 13 & 875 & & & $\begin{array}{l}\text { Unidentified - Multiple matching slip traces with } \\
\text { high Schmid factors }\end{array}$ \\
\hline Nodule 14 & 785 & Basal & 363.3 & \\
\hline Nodule 15 & 840 & Prismatic & 394.0 & \\
\hline Nodule 16 & 840 & Basal & 403.6 & \\
\hline Nodule 17 & & & & No slip trace detected \\
\hline Nodule 18 & 900 & Pyramidal & 421.5 & \\
\hline Nodule 19 & 920 & Basal & 426.5 & \\
\hline Nodule 20 & 785 & Basal & 378.7 & $\begin{array}{l}\text { Multiple matching slip traces with low Schmid } \\
\text { factors }(<0.25)\end{array}$ \\
\hline Nodule 21 & 935 & Prismatic & 376.2 & \\
\hline Nodule 22 & 900 & & & $\begin{array}{c}\text { Unidentified - Multiple matching slip traces with } \\
\text { high Schmid factors }\end{array}$ \\
\hline Nodule 23 & 840 & Basal & 370.9 & \\
\hline Nodule 24 & 900 & Prismatic & 430.1 & \\
\hline Nodule 25 & 900 & Prismatic & 402.1 & \\
\hline Nodule 26 & 920 & Prismatic & 343.0 & \\
\hline Nodule 27 & & & & No slip trace detected \\
\hline Nodule 28 & 840 & Pyramidal & 314.7 & \\
\hline Nodule 29 & 900 & Prismatic & 371.6 & \\
\hline Nodule 30 & 875 & Prismatic & 376.3 & \\
\hline Nodule 31 & 785 & Basal & 345.2 & \\
\hline Nodule 32 & 920 & Prismatic & 356.1 & \\
\hline Nodule 33 & 875 & Prismatic & 397.6 & $\begin{array}{l}\text { Other matching slip trace: pyramidal slip with } \\
\text { low Schmid factor }(<0.25)\end{array}$ \\
\hline Nodule 34 & 875 & Prismatic & 400.7 & \\
\hline
\end{tabular}

Table 1. Nodule number, applied stress at which slip traces were first detected, activated slip mode according to the slip trace analysis, apparent CRSS (determined using a global stress state) and supplementary remark for the 34 nodules considered

\subsection{Prediction of activated slip systems using lattice rotation data}

Deformation systems operating in nodules were then studied regarding lattice rotation data. According to the FSD micrographs, no slip activity was observed up to $750 \mathrm{MPa}$. Since only slipinduced rotation is used for the identification of operating slip systems, the angle of rotation of slipinduced rotation axes for basal and prismatic slip systems were calculated between the $750 \mathrm{MPa}$ step and the $970 \mathrm{MPa}$ step. This enables to limit the contribution of elastic deformation to the rotation of the slip-induced rotation axes while considering substantial rotation magnitudes. The results and the associated Schmid factors are presented in table 2. Since only one slip-induced rotation axis is associated with prismatic slip systems, only the highest Schmid factor is reported. A few nodules (2, 7,31 ) have been ruled out of the present analysis as crystal symmetries induced artificially large magnitudes of rotations (highlighted in grey in Table 2). For each nodule, the slip system with the lowest angle was predicted as activated (highlighted in green in table 2). The ratio of the associated Schmid factor to the maximum Schmid factor among basal and prismatic slip systems and the agreement with the operating slip mode identified according to the slip trace analysis are also 


\begin{tabular}{|c|c|c|c|c|c|c|c|c|c|c|c|}
\hline $\begin{array}{c}\text { Nodule } \\
\mathrm{N}^{\circ}\end{array}$ & $\begin{array}{l}\text { Basal } 1 \\
\text { Schmid } \\
\text { factor }\end{array}$ & $\begin{array}{l}\text { Basal } 1 \\
\text { rotation } \\
\left(\left(^{\circ}\right)\right.\end{array}$ & $\begin{array}{c}\text { Basal } 2 \\
\text { Schmid } \\
\text { factor }\end{array}$ & $\begin{array}{c}\text { Basal } 2 \\
\text { rotation } \\
\left(^{\circ}\right)\end{array}$ & $\begin{array}{l}\text { Basal } 3 \\
\text { Schmid } \\
\text { factor }\end{array}$ & $\begin{array}{c}\text { Basal } 3 \\
\text { rotation } \\
\left(^{\circ}\right)\end{array}$ & $\begin{array}{l}\text { Maximu } \\
\mathrm{m} \\
\text { prismatic } \\
\text { Schmid } \mathrm{f} \\
\text { actor }\end{array}$ & $\begin{array}{c}\text { Prismatic } \\
\text { rotation } \\
\left({ }^{\circ}\right)\end{array}$ & $\begin{array}{l}\text { Predicted } \\
\text { slip } \\
\text { system }\end{array}$ & $\begin{array}{c}\text { Predicted } \\
\text { SF / } \\
\text { Maximu } \\
\text { m SF }\end{array}$ & $\begin{array}{l}\text { Agreeme } \\
\text { nt with } \\
\text { slip } \\
\text { traces } \\
\text { analysis }\end{array}$ \\
\hline Nodule 1 & 0.388 & 0.689 & 0.072 & 1.089 & 0.460 & 0.385 & 0.208 & 1.090 & B3 & 1.000 & True \\
\hline Nodule 2 & 0.258 & 59.584 & 0.220 & 59.584 & 0.038 & 59.584 & 0.041 & 0.288 & & & \\
\hline Nodule 3 & 0.417 & 0.632 & 0.085 & 0.837 & 0.332 & 0.263 & 0.365 & 0.879 & B3 & 0.797 & - \\
\hline Nodule 4 & 0.499 & 0.000 & 0.262 & 1.573 & 0.237 & 1.552 & 0.213 & 1.817 & B1 & 1.000 & True \\
\hline Nodule 5 & 0.156 & 0.826 & 0.313 & 0.354 & 0.470 & 0.723 & 0.320 & 0.808 & B2 & 0.667 & True \\
\hline Nodule 6 & 0.483 & 0.445 & 0.239 & 1.241 & 0.244 & 1.079 & 0.161 & 1.217 & B1 & 1.000 & True \\
\hline Nodule 7 & 0.356 & 60.402 & 0.217 & 60.402 & 0.139 & 60.402 & 0.408 & 0.288 & & & \\
\hline Nodule 8 & 0.410 & 0.807 & 0.184 & 1.275 & 0.226 & 0.824 & 0.361 & 1.101 & B1 & 1.000 & - \\
\hline Nodule 9 & 0.290 & 0.632 & 0.014 & 0.596 & 0.276 & 0.641 & 0.055 & 0.352 & $\mathrm{P}$ & 0.191 & - \\
\hline $\begin{array}{c}\text { Nodule } \\
10\end{array}$ & 0.391 & 1.034 & 0.054 & 1.599 & 0.445 & 1.478 & 0.296 & 1.351 & B1 & 0.879 & True \\
\hline $\begin{array}{c}\text { Nodule } \\
11\end{array}$ & 0.413 & 0.866 & 0.434 & 0.385 & 0.021 & 1.122 & 0.272 & 1.141 & B2 & 1.000 & True \\
\hline $\begin{array}{c}\text { Nodule } \\
12\end{array}$ & 0.242 & 0.449 & 0.011 & 0.264 & 0.231 & 0.274 & 0.414 & 0.368 & B2 & 0.026 & False \\
\hline $\begin{array}{c}\text { Nodule } \\
13\end{array}$ & 0.366 & 0.161 & 0.085 & 1.518 & 0.451 & 1.454 & 0.317 & 1.683 & B1 & 0.812 & - \\
\hline $\begin{array}{c}\text { Nodule } \\
14\end{array}$ & 0.463 & 0.677 & 0.105 & 0.983 & 0.358 & 0.838 & 0.189 & 0.820 & B1 & 1.000 & True \\
\hline $\begin{array}{c}\text { Nodule } \\
15\end{array}$ & 0.112 & 0.514 & 0.016 & 0.709 & 0.128 & 0.571 & 0.469 & 0.451 & $\mathrm{P}$ & 1.000 & True \\
\hline $\begin{array}{c}\text { Nodule } \\
16\end{array}$ & 0.481 & 0.650 & 0.191 & 1.601 & 0.289 & 2.227 & 0.180 & 2.309 & B1 & 1.000 & True \\
\hline $\begin{array}{c}\text { Nodule } \\
17\end{array}$ & 0.460 & 0.258 & 0.064 & 1.187 & 0.396 & 1.199 & 0.219 & 1.347 & B1 & 1.000 & - \\
\hline $\begin{array}{c}\text { Nodule } \\
18\end{array}$ & 0.383 & 0.769 & 0.137 & 0.765 & 0.246 & 0.744 & 0.399 & 0.349 & $\mathrm{P}$ & 1.000 & - \\
\hline $\begin{array}{c}\text { Nodule } \\
19\end{array}$ & 0.462 & 0.261 & 0.372 & 0.873 & 0.090 & 1.047 & 0.296 & 1.118 & B1 & 1.000 & True \\
\hline $\begin{array}{c}\text { Nodule } \\
20\end{array}$ & 0.482 & 0.495 & 0.147 & 0.748 & 0.335 & 0.810 & 0.212 & 0.699 & B1 & 1.000 & True \\
\hline $\begin{array}{c}\text { Nodule } \\
21\end{array}$ & 0.379 & 0.000 & 0.244 & 0.630 & 0.135 & 0.606 & 0.402 & 0.708 & B1 & 0.943 & False \\
\hline $\begin{array}{c}\text { Nodule } \\
22\end{array}$ & 0.148 & 0.075 & 0.064 & 0.197 & 0.212 & 0.134 & 0.474 & 0.212 & B1 & 0.313 & - \\
\hline $\begin{array}{c}\text { Nodule } \\
23\end{array}$ & 0.442 & 0.437 & 0.135 & 0.934 & 0.307 & 0.986 & 0.143 & 1.008 & B1 & 1.000 & True \\
\hline $\begin{array}{c}\text { Nodule } \\
24\end{array}$ & 0.198 & 0.481 & 0.056 & 0.667 & 0.142 & 0.682 & 0.478 & 0.557 & B1 & 0.414 & False \\
\hline $\begin{array}{c}\text { Nodule } \\
25\end{array}$ & 0.197 & 0.479 & 0.027 & 0.432 & 0.224 & 0.385 & 0.447 & 0.265 & $\mathrm{P}$ & 1.000 & True \\
\hline Nodule & 0.419 & 0.461 & 0.107 & 0.464 & 0.312 & 0.577 & 0.372 & 0.453 & $\mathrm{P}$ & 0.888 & True \\
\hline
\end{tabular}




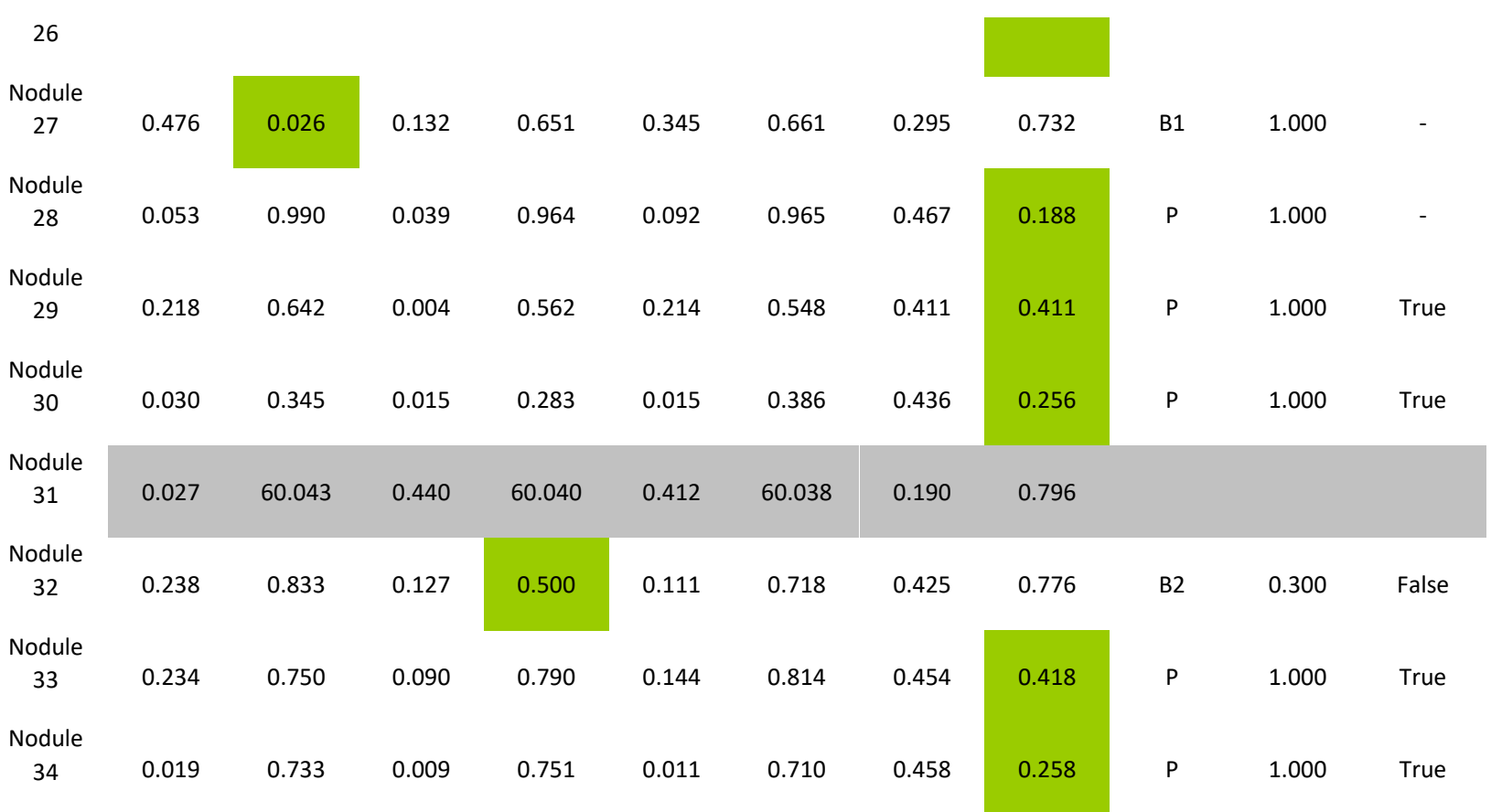

Table 2. Nodule number, Schmid factors and angle of rotation of slip-induced rotation axes between 750 MPa and $970 \mathrm{MPa}$ for basal and prismatic slip systems. The predicted slip system is highlighted in green. The ratio of its Schmid factor to the maximum Schmid factor and the agreement with slip traces analysis are also indicated.

The ratio of the Schmid factor associated with the slip system predicted as activated to the maximum Schmid factor among basal and prismatic slip systems is reported in table 2 . In most cases, the slip system which was predicted as activated using lattice rotations is the slip system with the highest Schmid Factor among the basal and prismatic slip systems. This is confirmed by the magnitude of the ratio, which is about 0.85 on average. According to the data presented in table 2 , the Schmid factor of the slip systems predicted as activated is about 0.38 on average. The Schmid factor being a well-established indicator of slip activation likeliness in titanium alloys [9], this value points out a consistent prediction of activated slip systems using lattice rotations.

A comparison with the results obtained using the slip trace analysis was also carried out. The agreement between the active slip mode predicted using lattice rotations and the active slip mode identified according to the slip trace analysis is indicated in table 2 . Since pyramidal slip systems have not been considered for the identification of active slip system using lattice rotations, only nodules exhibiting basal or prismatic slip traces are considered. A very good agreement is found with an $82 \%$ success rate of prediction. As a comparison, this value is typical of a slip trace analysis [10]. A disagreement between both approaches was found for nodules 12, 21, 24 and 32. Several potential causes have been identified. To begin with, the slip system prediction relies on a single slip assumption. A careful observation of the slip traces shown in figure $2 \mathrm{~b}$ suggests that most grains seem deformed by single slip at $970 \mathrm{MPa}$. Only 4 out of the 34 nodules present slip traces suggesting an activity of several slip systems (nodules $2,3,10$ and 30 ). However, no relation could be found with incorrect predictions. This may suggest that the slip system which is activated first dominates the lattice rotation behavior in the present conditions. A low rotation magnitude may also be an influential parameter. For instance, the angles of rotation associated with the slip-induced rotation axes of nodule 12 , which is associated with an erroneous prediction, are very small $\left(<0.45^{\circ}\right)$ and contained a restricted interval. These characteristics renders the analysis highly sensitive to rigidbody rotation, such as induced by surrounding grains. 
The slip trace analysis was presently considered as a reference procedure. However, an inherent bias is introduced. Hence, some predictions might be wrongly considered as 'incorrect'. For instance, a high Schmid factor is found for the slip system predicted as activated in nodule 21 using lattice rotations. The corresponding slip direction has a low component magnitude in the direction normal to the specimen surface ( $18 \%$ of the total magnitude). The associated slip traces may have been missed due to insufficiently high slip steps that caused the poor agreement between both active slip system identification techniques. This points out a major advantage of a lattice rotation based slip system identification: even slip leading to very small slip steps can be detected. In addition, a major drawback of slip traces based procedures is that the identification only relies on slip planes while slip directions are inferred. As a consequence, basal slip traces are often assumed as associated with the basal slip system with the highest Schmid factor $[9,10,35,38]$. The ratio of the basal Schmid factor identified using lattice rotations to the maximum basal Schmid factor was computed for successful basal slip predictions. The average value, which is about 0.96 , is very close to 1 . Hence, the aforementioned assumption, which is often used without verification, seems actually reasonable.

\subsection{Lattice rotation in nodules}
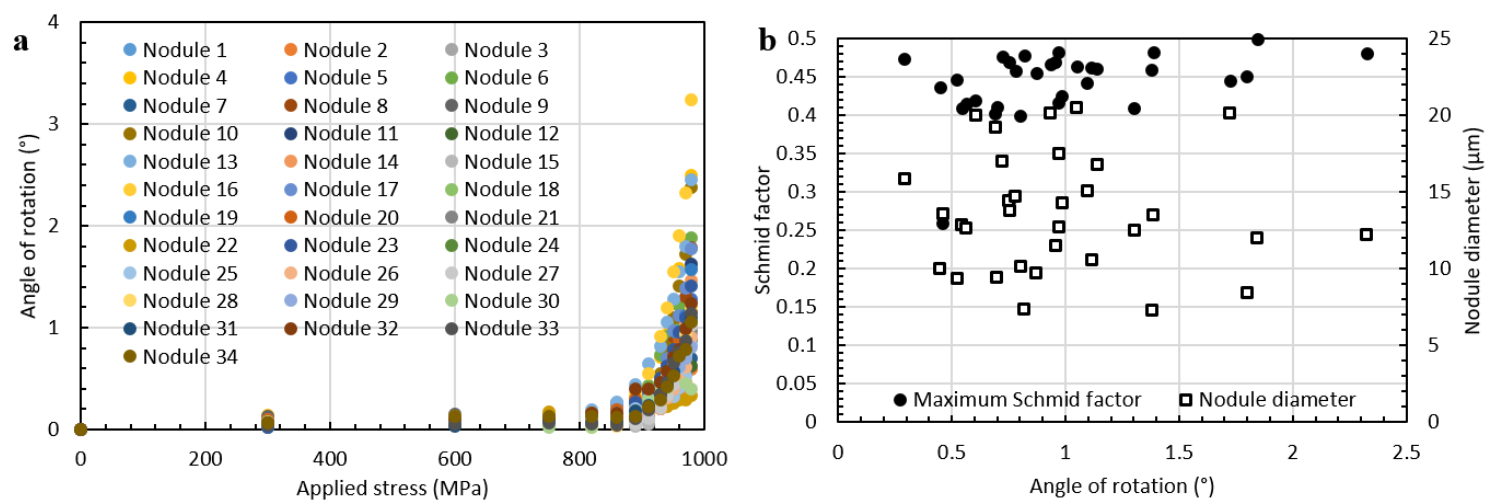

Figure 3 a. Average angle of rotation of each nodule, which is plotted against the applied stress, showing a sharp increase in magnitude at the onset of plastic slip and b. Schmid factor and nodule diameter plotted against the average angle of rotation of each nodule at the $970 \mathrm{MPa}$ step

Lattice rotation relative to the initial orientation was calculated at each loading step using equation (5). The angle of rotation is plotted against the applied stress in figure 3 a for each nodule. In the elastic regime, i.e. for an applied stress below $820 \mathrm{MPa}$, the angles of rotation remain below $0.2^{\circ}$. A subtle and progressive increase of the average value was noticed from $0.065^{\circ}$ at $300 \mathrm{MPa}$ to $0.094^{\circ}$ at $750 \mathrm{MPa}$. A marked increase in the angle of rotation is coincident with the onset of slip activity, i.e. for an applied stress higher than $750 \mathrm{MPa}$ according to the slip trace analysis. At 978 $\mathrm{MPa}$, the nodule with the highest magnitude of rotation experienced a $3.3^{\circ}$ rotation while the nodule with the lowest magnitude of rotation experienced a $0.4^{\circ}$ rotation. The magnitude of the rotations in the elastic regime are thus small compared to the magnitude of the rotations associated with roughly $2 \%$ plastic strain. In addition, the spread of the values obtained at $978 \mathrm{MPa}$ testifies of a highly heterogeneous rotation behavior in the plastic regime.

In order to identify factors potentially accounting for such dispersion, the influence of several parameters was examined. The effect of the nodule size was investigated first. Indeed, the grain size is highly influent on deformation owing to a high strength associated with low grain sizes $[39,40]$. The diameter of each nodule is plotted with respect to the angle of rotation at $970 \mathrm{MPa}$ in figure $3 \mathrm{~b}$. No marked effect of the nodule size could be found in the present conditions. Multiple prior studies showed that the Schmid factor is highly correlated with slip activity in titanium alloys. The influence 
of this parameter on the rotation magnitude was then investigated. The maximum Schmid factor among basal and prismatic slip systems for each nodule was plotted with respect to the angle of rotation at $970 \mathrm{MPa}$ in figure $3 \mathrm{~b}$. The nodules with a high angle of rotation exhibit high maximum Schmid factors while nodules with a low maximum Schmid factor are associated with low angles of rotation. Notwithstanding, nodules with a high maximum Schmid factor also occasionally exhibit low angles of rotation. Thus, these parameters seem insufficient to fully account for the dispersions previously highlighted.
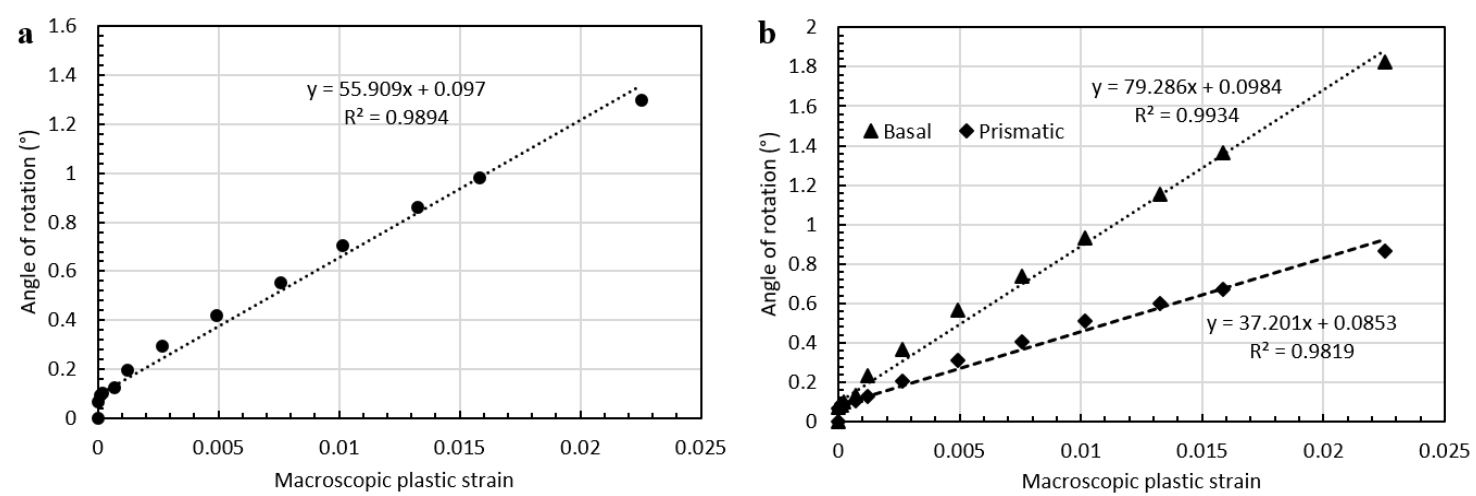

Figure 4 a. Average angle of rotation over the 34 nodules showing a linear dependence with respect to macroscopic plastic strain, b. Angle of rotation averaged over nodules exhibiting basal or prismatic slip activity and plotted against macroscopic plastic strain. Significantly different rotation behaviors are evidenced.

The angle of lattice rotation relative to the initial orientation was then averaged over the 34 nodules considered and plotted against the macroscopic plastic strain in figure 4 a. An offset about $0.1^{\circ}$ is observed at the end of the elastic regime. Beyond, the average angle of rotation increases linearly with respect to the macroscopic plastic strain. A $56^{\circ}$ slope is obtained using a linear regression. The value of the regression coefficient, which is about 0.989 , indicates a very good fit to the experimental data. This result confirms the direct relationship between the plastic strain magnitude and the magnitude of lattice rotations. In the following, the set of nodules is split into subsets in order to probe the effect of the operating slip mode on the lattice rotation behavior as well as the related plastic strain partitioning.

A potential difference in the lattice rotation behavior of nodules with operating basal or prismatic slip systems was first investigated. In order to retain solely nodules with confidently identified slip systems, only nodules with a similar slip mode predicted using slip traces analysis and lattice rotations were considered. 11 nodules are contained in the subset corresponding to basal slip while 7 nodules are contained in the subset corresponding to prismatic slip. The angles of rotation relative to the initial orientation were averaged over each subset of nodules. The resulting values are plotted against the macroscopic plastic strain in figure $4 \mathrm{~b}$. For each subset, a linear relationship between the average angle of rotation and the plastic strain magnitude is noticed. Linear regressions are associated with coefficients higher than 0.98 . These values indicate very good fits to the experimental data. The slope is about $79^{\circ}$ for the subset associated with basal slip while the slope is about $37^{\circ}$ for the subset associated with prismatic slip. This significant difference highlights a strong dependence of the lattice rotation behavior on the operating slip mode.

\subsection{Lattice rotation in colonies}



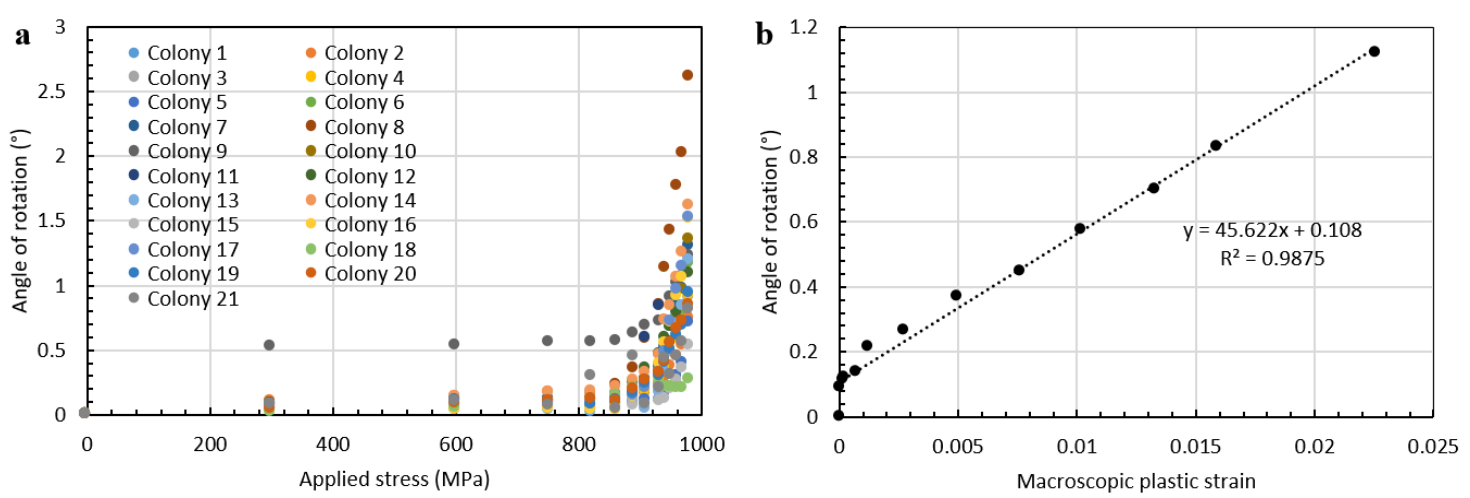

Figure 5 a. Average angle of rotation of each colony, which is plotted against the macroscopic plastic strain, showing a sharp increase in magnitude at the onset of plastic slip and $b$. Angle of rotation averaged over the

21 colonies and plotted against the macroscopic plastic strain. A linear dependence with respect to the macroscopic plastic strain is noticed. The magnitude of the slope is lower than the one obtained for nodules.

According to prior studies, nodules and colonies exhibit different deformation behaviors. As a consequence, a potential difference in the lattice rotation behaviors was investigated. 3 colonies were ruled out of the present analysis as crystal symmetries induced artificially large magnitude of rotations. The angle of rotation relative to the initial orientation is plotted against the applied stress in figure 5 a. The same qualitative trends as for nodules are observed. In average, the angle of rotation is low for a macroscopic applied stress lower than $820 \mathrm{MPa}$. A sudden increase in the angle of rotation is coincident with the onset of macroscopic yield. In order to quantitatively assess the average lattice rotation behavior in colonies, the angle of rotation relative to the initial orientation was averaged at each step over the 18 colonies considered. The resulting values are plotted against the macroscopic plastic strain in figure $5 \mathrm{~b}$. The average angle of rotation increases linearly with respect to the macroscopic plastic strain. As a consequence, a linear regression was applied to enable a quantified comparison with the lattice rotation behavior of nodules. According to the regression coefficient $(\approx 0.988)$, a very good fit to the data is obtained with a $46^{\circ}$ slope. This value is lower than the one previously established considering nodules only. Hence, the rotation of colonies appears more difficult than the rotation of nodules for a given macroscopic plastic strain increment. Concurrently, the average angle of rotation is lower for colonies than for nodules considering a similar macroscopic plastic strain. For instance, under an applied stress of $970 \mathrm{MPa}$, the average angle of rotation is about $0.82^{\circ}$ for colonies versus $0.98^{\circ}$ for nodules. The origins of these differences are discussed in the next section.

Finally, a potential difference in the lattice rotation behavior of colonies with operating basal or prismatic slip systems was investigated. A slip trace analysis was carried out in order to identify the operating slip systems. Among the 21 colonies considered, slip traces were confidently assigned to a prismatic slip system for 7 colonies and to a basal slip system for 4 colonies. An operating slip mode could not be identified for 10 colonies. Slip traces were either absent or not confidently assigned to a basal or prismatic slip system. The restricted number of cases presently considered ruled out any reliable apparent CRSS estimation.

At each step, the angle of rotation relative to the initial orientation was averaged over colonies with a similar operating slip mode. The resulting values are plotted against the macroscopic plastic strain in figure 6 . The average angles of rotation associated with the operation of basal slip are slightly higher than the average angles of rotation associated with the operation of prismatic slip. For instance, under an applied stress of $970 \mathrm{MPa}$, the angles are $0.75^{\circ}$ for prismatic slip and $0.82^{\circ}$ for basal slip. A linear regression was applied to both datasets. Regression coefficients about 0.966 and 
0.990 were obtained for basal and prismatic slip respectively. These values, which are very close to 1 , indicate a good fit to the data. A slope of $46^{\circ}$ was obtained for the subset of colonies associated with the operation of basal slip while a slope of $43^{\circ}$ was obtained for the subset of colonies associated with the operation of prismatic slip. As with nodules, the subset associated with basal slip exhibits a higher slope than the subset associated with prismatic slip. However, the difference in the slope values is substantially decreased. Using the slope of the subset associated with the operation of basal slip as a reference, the slope corresponding to the subset associated with the operation of prismatic slip is $53 \%$ lower for nodules while only $6 \%$ lower for colonies. Hence, the differences in the lattice rotation behavior between basal and prismatic slip modes seem mitigated if colonies are considered. Owing to the limited number of colonies presently considered, the previous analysis was repeated in a neighboring region. The data, which are not shown here for clarity purposes, support the previous findings.

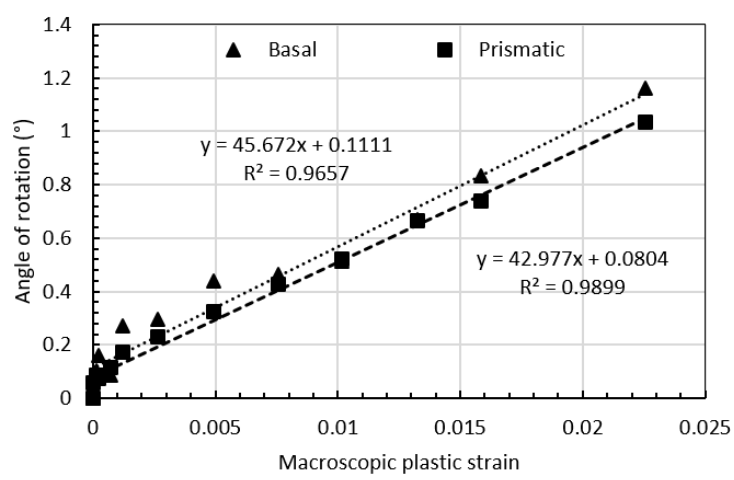

Figure 6. Angle of rotation averaged over colonies exhibiting basal or prismatic slip activity and plotted against macroscopic plastic strain

\section{Discussion}

\subsection{Identification of deformation processes using lattice rotations}

Local lattice rotations were characterized up to about $2 \%$ plastic strain using an in situ EBSD tensile test. Based on this data, the identification of active deformation systems was undertaken. A good agreement was found with a slip trace analysis, which is a more conventional procedure. The following conclusions ensue: i) the rigid body rotations resulting from processes such as specimen realignment under loading or grain shape rotations induced by neighboring grains appear as having a minor contribution to the measured lattice rotations, even if a single grain is considered. ii) In contrast, intragranular plastic slip has a dominant contribution to the measured lattice rotations. Interestingly, the occasional operation of two slip systems in a single nodule did not disrupt the analysis, which is based on a single slip assumption. This observation may suggest that the first slip system to be activated dominates the slip-induced lattice rotation.

The main advantage offered by the lattice rotation based procedure is the discrimination of slip systems sharing the same slip plane. For instance, basal slip systems could be differentiated regarding slip directions. In contrast, slip trace analysis usually relies on strong assumptions to identify the active slip system since the slip trace only reflects the slip plane. Basal slip traces are often assumed to correspond to the basal slip system with the highest Schmid factor $[9,10,36]$. The present lattice rotation based analysis showed that this hypothesis is actually consistent with experimental observations. However, some limitations, which are discussed hereafter, are inherent to the method. 
Despite the promising results obtained, occasional misidentification of slip systems are suspected. Criteria and confidence indices have yet to be introduced in order to obtain a robust analysis of deformation systems. Although further work is required in this direction, several parameters can be readily identified as affecting the reliability of the prediction. The operating slip system being identified according to the angle of rotation of slip induced rotation axes, predictions should be given credit provided the magnitude of lattice rotations are higher than a given angular threshold. This threshold is partly related to the repeatability of orientation measurements. Such values are lower than the classical value of $0.5^{\circ}$ for EBSD angular resolution owing to the averaging approach presently applied [41]. As shown in Appendix I, the scatter in the data is small, with the rotation from one measured orientation to another being on average $0.02^{\circ}$, and at most $0.05^{\circ}$. In turn, this enabled an improved determination of the rotation axis for small rotation angles compared to single orientation measurements. The reader is referred to Appendix I for further details. Since the orientations used in the present analyses result from averaging over hundreds of single orientation measurements carried out in a single grain, the number of orientation measurements performed inside a single grain is also a parameter that has to be considered. Besides, any assessment of slip activation kinetics is still a challenge due to a difficult detection of slip activation. Improved precision could be attained using optimized EBSD acquisition settings [42], improved Kikuchi patterns indexing techniques [43] or cross-correlation based high angular resolution EBSD [41].

Some erroneous identifications of slip systems may also be ascribed to the influence of rigidbody rotations. For instance, these rotations are the result of the loading conditions of the specimen, which cannot allow a prefect alignment of the specimen with the EBSD frame during the whole duration of the tensile test, and the presence of the free surface, which implies an incomplete constraint of nodules and colonies. As a consequence, the measured rotation axis may somewhat deviate from the expected one. The contribution related to rigid body rotations may thus be noticeable if small angles of rotation are involved. Finally, the number of potential slip systems, which is tightly related to the number of slip induced rotation axes, controls the complexity of the lattice rotation behavior. The higher the number of potential slip systems is, the more subtle the discrimination between the angles of rotation of the slip induced rotation axes is. This is another limitation of this procedure.

\subsection{Towards a quantitative assessment of plastic strain?}

In situ characterization of lattice rotations during tensile deformation highlighted a linear relation between the average angle of lattice rotation relative to the initial orientation and the macroscopic plastic strain. Such a correlation is consistent with data reported in prior studies focusing on X-ray diffraction characterization of lattice rotations in 316 stainless steel [29] and in commercial purity titanium [32]. The crystal plasticity models involving equation (2) can also predict this feature provided the following conditions are met: i) single slip conditions, ii) a negligible influence of rigid-body spins and iii) a limited evolution of the skew-symmetric Schmid tensor with deformation (i.e. of the crystallographic orientations). These conditions being satisfied in the present work, lattice rotations measured using in situ EBSD can be used to assess strain partitioning in Ti-6Al$4 \mathrm{~V}$. The relation between the lattice rotation and the plastic strain is discussed in the following.

Equation (2) leads to a direct relationship between the plastic shear rate $\dot{\gamma}$ and the lattice rotation rate $\boldsymbol{W}^{*}$. Equation (7), which is defined below, can be used for time integration [33].

$$
\boldsymbol{R}_{\mathbf{0}, \boldsymbol{j}}=\boldsymbol{R}_{\mathbf{0}, \boldsymbol{i}} \exp \left(\boldsymbol{W}^{*} \Delta t\right)
$$

The relationship between the shear on the active slip system and the magnitude of lattice rotation is straightforward. A linear relation with a slope about $28.6^{\circ}$ is analytically predicted. 
Accordingly, the measured angles of lattice rotation can be converted into apparent plastic shear strain magnitudes. The average angles of rotation previously obtained were converted into apparent plastic shear strain and plotted in figure 7 against the macroscopic plastic strain. The apparent shear strain magnitudes are discussed in the following subsection (4.3) regarding microstructural features and active slip modes.

482

483

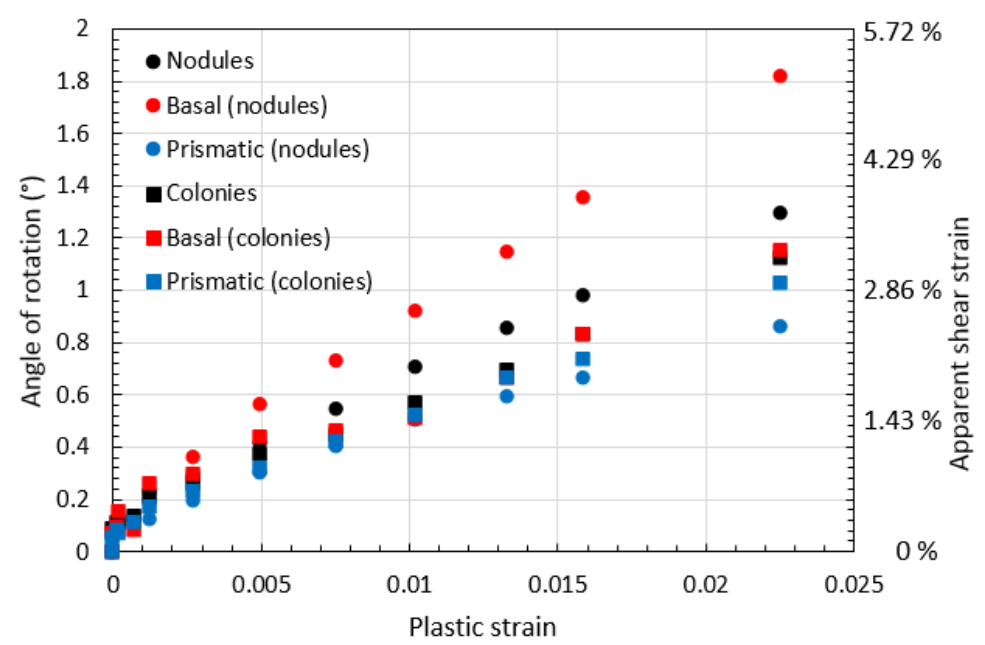

Figure 7: Average angle of rotation and estimated plastic shear strain plotted against the macroscopic plastic strain, showing a significant plastic strain partitioning

The macroscopic plastic strain, which was experimentally estimated using the crosshead displacement, can be used to confirm the relevancy of the obtained estimates. A relationship with the lattice rotation, which is extracted from the EBSD data, is searched in the following. To begin with, the Schmid tensor relates the plastic shear rate $\dot{\gamma}_{i}$ on slip system $i$ with the plastic strain rate tensor $\left(\dot{\varepsilon}_{P}\right)$ as shown in equation (8):

$\dot{\boldsymbol{\varepsilon}}_{\boldsymbol{P}}=\sum_{i=1}^{N} \frac{1}{2}\left(\boldsymbol{s}_{\boldsymbol{i}} \otimes \boldsymbol{m}_{\boldsymbol{i}}+\boldsymbol{m}_{\boldsymbol{i}} \otimes \boldsymbol{s}_{\boldsymbol{i}}\right) \dot{\gamma}_{i}$

With $\boldsymbol{s}_{\boldsymbol{i}}$ the slip plane normal associated with slip system $i$ in the sample frame and $\boldsymbol{m}_{\boldsymbol{i}}$ the slip direction associated with slip system $i$ in the sample frame. Assuming a negligible evolution of the Schmid tensor, a direct relationship between the plastic strain in the loading direction $\left(\varepsilon_{P}\right)$, the apparent Schmid factor of the active slip system $(S F)$ and the plastic shear strain $(\gamma)$ is obtained after time integration and shown in equation (9):

$\varepsilon_{P}=S F \cdot \gamma$

Then, a relationship between the macroscopic plastic strain $\left(\bar{\varepsilon}_{P}\right)$ and the local plastic strain $\left(\varepsilon_{P}\right)$ is required. The macroscopic plastic strain $\left(\bar{\varepsilon}_{P}\right)$ can be decomposed as follows:

$\bar{\varepsilon}_{P}=\bar{\varepsilon}_{P}^{\text {Nodules }} \cdot f_{S}^{\text {Nodules }}+\bar{\varepsilon}_{P}^{\text {Colonies }} \cdot f_{S}^{\text {Colonies }}$

With $\bar{\varepsilon}_{P}^{\text {Nodules }}$ the average plastic strain experienced by nodules, $\bar{\varepsilon}_{P}^{\text {Colonies }}$ the average plastic strain experienced by colonies, $f_{S}^{\text {Nodules }}$ the surface fraction associated with nodules and $f_{S}^{\text {Colonies }}$ the surface fraction associated with colonies. The average plastic strain in each type of microstructural element (i.e. nodule or colony) is then calculated using measured lattice rotations. It is computed as the arithmetic average of the plastic strain $\varepsilon_{P}$ over a given type of microstructural element, which is expressed as follows using equations (7) and (9). 
With I being the type of microstructural element (i.e. nodule or colony), 6 the constant $\left(\approx 28.6^{\circ}\right.$ ) previously introduced which enables the conversion of shear strain into a magnitude of lattice rotation, $n_{1}$ the number of nodules or colonies considered, $S F_{k}$ the Schmid factor of the nodule / colony $k$ and $\theta_{k}$ the measured lattice rotation magnitude of nodule / colony $k$. Considering only the microstructural elements associated with a basal or prismatic slip systems confidently identified, the average plastic strain was estimated at each loading step using the angle of lattice rotations. The resulting values are plotted in figure 8 with respect to the macroscopic plastic strain, which was estimated using the crosshead displacement. The $x=y$ line is also indicated.

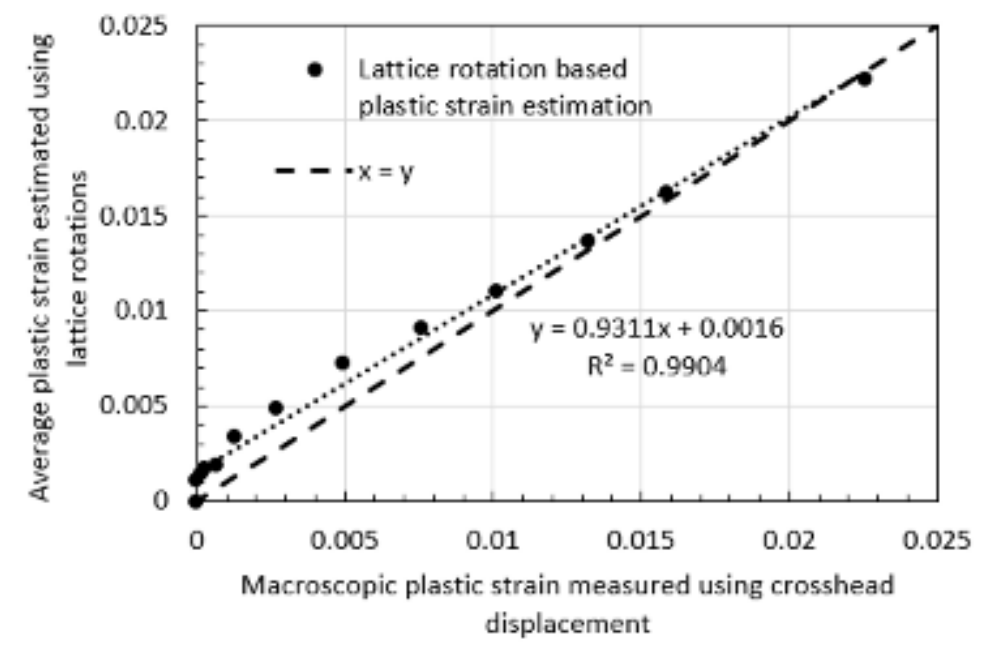

Figure 8: Average plastic strain, which is estimated using lattice rotations, plotted against the macroscopic plastic strain, which is estimated using the crosshead displacement, showing a good agreement according to the $x=y$ line and the slope of the linear regression

The average plastic strain estimated using lattice rotations is very close to the value obtained using the crosshead displacement. In order to dismiss the influence of the angular offset in the elastic regime, which is composed of rigid body and elastic rotations, a linear regression was applied. The resulting slope is about 0.93 , which is very close to 1 . This very good agreement shows that a semiquantitative estimation of the plastic strain at the microstructural scale (i.e. for a set of grains) can be performed using the presently proposed procedure. Further investigations are required for a thorough assessment of the accuracy of this procedure for both individual and sets of grains. Notably, the macroscopic strain estimation procedure could be improved using digital image correlation or strain gages. In addition, non-deforming nodules, or colonies, have not been considered. These points are left for future work.

\subsection{Lattice rotations and strain partitioning in Ti-6Al-4V}

While the nodule size and the maximum Schmid factor failed at accounting for the dispersions in the magnitude of lattice rotation relative to the initial orientation, strikingly different behaviors were evidenced by differentiating microstructural elements (i.e. nodules and colonies) and active slip modes (i.e. basal and prismatic slip). These results, which have been previously discussed in terms of lattice rotation, are interpreted hereafter in terms of strain partitioning. In average, basal slip is associated with higher angles of rotation than prismatic slip for a given macroscopic plastic strain level. This observation suggests that, in average, a higher plastic strain magnitude is experienced by a microstructural element deforming by basal slip than by a similar microstructural 
element deforming by prismatic slip. This is illustrated in figure 7 in terms of apparent plastic shear strain. Hence, plastic strain seems to be heterogeneously distributed depending on the active slip mode. This characteristic might be a consequence of the activation of basal slip at lower applied stress than prismatic slip $[10,37,44]$. However, the differences in CRSS values are small, i.e. typically a few percents $[4,44,45]$. A different strain hardening/softening behavior depending on the slip system considered might also significantly contribute to the strain partitioning. Prior studies based on experimental observations revealed a more pronounced strain softening for basal slip than for prismatic slip $[46,47]$. This characteristic might also significantly contribute to the differences in rotation and deformation behaviors at the grain scale.

Similarly, lattice rotation data suggests a marked strain partitioning between nodules and colonies. As illustrated in figure 7 , the magnitude of average plastic strain in colonies appear lower than in nodules. The slow increase in plastic strain experienced by colonies is an evidence of the impediment of dislocation motion by $\beta$ layers. Moreover, the basal / prismatic related strain partitioning, which is marked in nodules, appears significantly reduced in colonies. This observation results from interactions of dislocations of basal or prismatic slip systems with $\beta$ layers. A more mechanistic understanding of these observations and of the effect on the heterogeneity of mechanical fields requires additional experimental characterizations as well as numerical simulations.

Over the last decades, much efforts have been put into CRSS estimation in order to obtain realistic crystal plasticity simulations [4,34,44]. As pointed out in a recent study [48], little data is available about the deformation behavior beyond slip initiation. In this context, lattice rotation data extracted using in situ EBSD are obviously valuable inputs for polycrystal plasticity simulations. Direct comparison of lattice rotation data with simulation results and parameter optimization is on-going for a quantitative assessment of strain partitioning. This constitutes a key milestone in a microstructure optimization framework as strain partitioning is well-known to have important consequences on the material performance through stress redistribution and slip induced damage processes [49-51].

\section{$\underline{5 \text { Conclusions }}$}

Lattice rotations were characterized in situ during tensile deformation of a Ti-6Al-4V specimen using EBSD. A direct relation with plastic deformation at the microstructure scale was evidenced. To begin with, the rotation axis was used for the identification of the active slip system. The good agreement with a conventional slip trace analysis revealed a consistent identification of operating slip systems while complementary information, such as the slip direction, could be obtained. It enabled to demonstrate the widespread assumption that the basal slip traces most often corresponds to the slip system with the highest Schmid factor. This analysis also revealed a dominant contribution of intragranular plastic slip to the global lattice rotation behavior. In contrast, the contribution of rigid body rotations appears as secondary in the present conditions. Besides, the magnitude of the lattice rotation relative to the initial orientation exhibits a linear relationship with the plastic strain. This relation, which could be expected from classical crystal plasticity laws, offers insights into a direct quantification of the plastic strain at the microstructure scale using lattice rotation data. In agreement with previous investigations, a marked strain partitioning was evidenced between nodules and colonies. The operating slip mode was also identified as a factor of prime influence on strain partitioning. Nodules with operating basal slip experience, in average, a higher 


\section{Declarations of interest: none}

\section{6}

\section{$\underline{6 \text { References }}$}

588 [1] C. Leyens, M. Peters, Titanium and Titanium Alloys: Fundamentals and Applications, John Wiley \& Sons, 2006.

589 [2] G. Lütjering, J.C. Williams, Titanium, 2nd edition, Springer, Berlin; New York, 2007.

590 [3] G. Lütjering, Influence of processing on microstructure and mechanical properties of $(\alpha+\beta)$ titanium alloys, Mater. Sci.

591 Eng.: A-Struct. 243 (1998) 32-45.

592 [4] S. Hémery, P. Villechaise, Investigation of Size Effects in Slip Strength of Titanium Alloys: Alpha Nodule Size Dependence 593 of the Critical Resolved Shear Stress, Metall. Mater. Trans. A (2018) 1-4.

594 [5] M.R. Bache, W.J. Evans, Impact of texture on mechanical properties in an advanced titanium alloy, Mater. Sci. Eng.: A595 Struct. 319-321 (2001) 409-414.

596 [6] D. Lunt, J.Q. da Fonseca, D. Rugg, M. Preuss, Microscopic strain localisation in Ti-6Al-4V during uniaxial tensile loading, 597 Mater. Sci. Eng.: A-Struct. 680 (2017) 444-453.

598 [7] A. Radecka, J. Coakley, I.P. Jones, D. Rugg, T.C. Lindley, D. Dye, Ordering and the micromechanics of Ti-7Al, Mater. Sci. 599 Eng.: A-Struct. 650 (2016) 28-37.

600 [8] P. Castany, F. Pettinari-Sturmel, J. Douin, A. Coujou, TEM quantitative characterization of short-range order and its 601 effects on the deformation micromechanims in a Ti-6Al-4V alloy, Mater. Sci. Eng.: A-Struct. 680 (2017) 85-91.

[9] F. Bridier, P. Villechaise, J. Mendez, Analysis of the different slip systems activated by tension in a $\alpha / \beta$ titanium alloy in relation with local crystallographic orientation, Acta Mater. 53 (2005) 555-567.

604 [10] S. Hémery, P. Villechaise, On the influence of ageing on the onset of plastic slip in Ti-6AI-4V at room temperature: 605 Insight on dwell fatigue behavior, Scripta Mater. 130 (2017) 157-160.

606 [11] S. Hémery, P. Villechaise, Comparison of slip system activation in Ti-6Al-2Sn-4Zr-2Mo and Ti-6Al-2Sn-4Zr-6Mo under tensile, fatigue and dwell-fatigue loadings, Mater. Sci. Eng.: A-Struct. 697 (2017) 177-183.

[12] S. Hémery, P. Villechaise, Influence of $\beta$ anisotropy on deformation processes operating in Ti-5Al-5Mo-5V-3Cr at room temperature, Acta Mater. 141 (2017) 285-293.

610 [13]S. Zhang, W. Zeng, Q. Zhao, L. Ge, M. Zhang, In situ SEM study of tensile deformation of a near- $\beta$ titanium alloy, Mater.

611 Sci. Eng.: A-Struct. 708 (2017) 574-581.

[14] D. Deka, D.S. Joseph, S. Ghosh, M.J. Mills, Crystal plasticity modeling of deformation and creep in polycrystalline Ti6242, Metall. Mater. Trans. A 37 (2006) 1371-1388.

[15] F. Bridier, D.L. McDowell, P. Villechaise, J. Mendez, Crystal plasticity modeling of slip activity in Ti-6Al-4V under high cycle fatigue loading, Int. J. Plasticity 25 (2009) 1066-1082.

[16] I.P. Jones, W.B. Hutchinson, Stress-state dependence of slip in Titanium-6AI-4V and other H.C.P. metals, Acta Metall. 29 (1981) 951-968.

[17] V. Hasija, S. Ghosh, M.J. Mills, D.S. Joseph, Deformation and creep modeling in polycrystalline Ti-6Al alloys, Acta Mater. 61951 (2003) 4533-4549.

620 [18] P.R. Dawson, D.E. Boyce, J.-S. Park, E. Wielewski, M.P. Miller, Determining the strengths of HCP slip systems using 621 harmonic analyses of lattice strain distributions, Acta Mater. 144 (2018) 92-106. 
[20] F.P.E. Dunne, D. Rugg, A. Walker, Lengthscale-dependent, elastically anisotropic, physically-based hcp crystal plasticity: Application to cold-dwell fatigue in Ti alloys, Int. J. Plasticity 23 (2007) 1061-1083.

[21] P.D. Littlewood, A.J. Wilkinson, Local deformation patterns in Ti-6Al-4V under tensile, fatigue and dwell fatigue loading, Int. J. Fatigue 43 (2012) 111-119.

[22] A.J. Wilkinson, T.B. Britton, Strains, planes, and EBSD in materials science, Mater. Today 15 (2012) 366-376.

[23] A.J. Wilkinson, Measuring Strains Using Electron Backscatter Diffraction, in: Electron Backscatter Diffraction in Materials Science, Springer, Boston, MA, 2000: pp. 231-246.

[24] S.I. Wright, M.M. Nowell, D.P. Field, A Review of Strain Analysis Using Electron Backscatter Diffraction, Microsc. Microanal. 17 (2011) 316-329.

[25] N.C. Krieger Lassen, D. Juul Jensen, K. Condradsen, Automatic Recognition of Deformed and Recrystallized Regions in Partly Recrystallized Samples Using Electron Back Scattering Patterns, Mater. Sci. Forum (1994).

[26] D.P. Field, Quantification of partially recrystallized polycrystals using electron backscatter diffraction, Mater. Sci. Eng.: A-Struct. 190 (1995) 241-246.

[27] M. Kamaya, A.J. Wilkinson, J.M. Titchmarsh, Quantification of plastic strain of stainless steel and nickel alloy by electron backscatter diffraction, Acta Mater. 54 (2006) 539-548.

[28] M. Kamaya, Measurement of local plastic strain distribution of stainless steel by electron backscatter diffraction, Mater. Charact. 60 (2009) 125-132.

[29] L. Margulies, G. Winther, H.F. Poulsen, In Situ Measurement of Grain Rotation During Deformation of Polycrystals, Science 291 (2001) 2392-2394.

[30] G. Winther, Slip systems extracted from lattice rotations and dislocation structures, Acta Mater. 56 (2008) $1919-1932$.

[31] P. Chen, S.C. Mao, Y. Liu, F. Wang, Y.F. Zhang, Z. Zhang, X.D. Han, In-situ EBSD study of the active slip systems and lattice rotation behavior of surface grains in aluminum alloy during tensile deformation, Mater. Sci. Eng.: A-Struct. 580 (2013) 114-124.

[32] L. Wang, Z. Zheng, H. Phukan, P. Kenesei, J.-S. Park, J. Lind, R.M. Suter, T.R. Bieler, Direct measurement of critical resolved shear stress of prismatic and basal slip in polycrystalline Ti using high energy X-ray diffraction microscopy, Acta Mate. 132 (2017) 598-610.

[33] U.F. Kocks, C.N. Tomé, H.-R. Wenk, A.J. Beaudoin, Texture and Anisotropy: Preferred Orientations in Polycrystals and Their Effect on Materials Properties, Cambridge University Press, 2000.

[34] H. Li, D.E. Mason, T.R. Bieler, C.J. Boehlert, M.A. Crimp, Methodology for estimating the critical resolved shear stress ratios of $\alpha$-phase Ti using EBSD-based trace analysis, Acta Mater. 61 (2013) 7555-7567.

[35] D. Lunt, T. Busolo, X. Xu, J. Quinta da Fonseca, M. Preuss, Effect of nanoscale $\alpha 2$ precipitation on strain localisation in a two-phase Ti-alloy, Acta Mater. 129 (2017) 72-82.

[36] S. Hémery, V.T. Dang, L. Signor, P. Villechaise, Influence of Microtexture on Early Plastic Slip Activity in Ti-6Al-4V Polycrystals, Metall. Mater. Trans. A (2018) 1-9.

[37] S. Hémery, A. Nait-Ali, P. Villechaise, Combination of in-situ SEM tensile test and FFT-based crystal elasticity simulations of Ti-6Al-4V for an improved description of the onset of plastic slip, Mech. Mater. 109 (2017) 1-10.

[38] B. Barkia, V. Doquet, J.P. Couzinié, I. Guillot, E. Héripré, In situ monitoring of the deformation mechanisms in titanium with different oxygen contents, Mater. Sci. Eng.: A-Struct. 636 (2015) 91-102.

[39] E.O. Hall, Proc. Phys. Soc. Lond B 64 (1951) 747-753.

[40] N.J. Petch, J. Iron Steel Inst. 174 (1953) 25-28.

[41] A.J. Wilkinson, A new method for determining small misorientations from electron back scatter diffraction patterns, Scripta Mater. 44 (2001) 2379-2385.

[42] I. Brough, P.S. Bate, F.J. Humphreys, Optimising the angular resolution of EBSD, Mater. Sci. Tech. 22 (2006) 1279-1286. 
[43] T.B. Britton, V.S. Tong, J. Hickey, A. Foden, A.J. Wilkinson, AstroEBSD: exploring new space in pattern indexing with

669 [44] M. Kasemer, M.P. Echlin, J.C. Stinville, T.M. Pollock, P. Dawson, On slip initiation in equiaxed $\alpha / \beta$ Ti-6Al-4V, Acta Mater.

$670136(2017) 288-302$.

671 [45] J.C. Williams, R.G. Baggerly, N.E. Paton, Deformation behavior of HCP Ti-Al alloy single crystals, Metall. Mater. Trans. A $67233(2002) 837-850$.

673 [46] K. May, Small Scale Tensile Testing of Titanium Alloys (Master's thesis), The Ohio State University (2010).

674 [47] D.C. Pagan, P.A. Shade, N.R. Barton, J.-S. Park, P. Kenesei, D.B. Menasche, J.V. Bernier, Modeling slip system strength 675 evolution in Ti-7Al informed by in-situ grain stress measurements, Acta Mater. 128 (2017) 406-417.

676 [48] K. Kapoor, M.D. Sangid, Initializing type-2 residual stresses in crystal plasticity finite element simulations utilizing high677 energy diffraction microscopy data, Mater. Sci. Eng.: A-Struct. 729 (2018) 53-63.

678 [49] W.J. Evans, M.R. Bache, Dwell-sensitive fatigue under biaxial loads in the near-alpha titanium alloy IMI685, Int. J.

679 Fatigue 16 (1994) 443-452.

680 [50] F.P.E. Dunne, A. Walker, D. Rugg, A systematic study of hcp crystal orientation and morphology effects in polycrystal

681 deformation and fatigue, P. Roy. Soc. Lon. A Mat. 463 (2007) 1467-1489.

682 [51] M. Anahid, M.K. Samal, S. Ghosh, Dwell fatigue crack nucleation model based on crystal plasticity finite element simulations of polycrystalline titanium alloys, J. Mech. Phys. Solids 59 (2011) 2157-2176.

The analysis of deformation processes described in the present work is based on averaging to reduce uncertainty in orientation measurement using conventional EBSD characterization. Considering conventional EBSD measurements and assuming a standard deviation of about $0.5^{\circ}$ for individual measurements [], the standard deviation of the average orientation would be about $0.02^{\circ}$ since the nodules presently considered contain at least 500 data points. This was experimentally confirmed by characterizing the same region twice using the same EBSD settings as given previously. The misorientation between the average orientations of a given grain was calculated using the two sets of orientation data. These values are reported in table A.1. The average misorientation is about $0.02^{\circ}$ and the maximum is about $0.05^{\circ}$. This is consistent with the order of magnitude previously mentioned.

\begin{tabular}{|c|c|}
\hline Nodule 1 & $0.002^{\circ}$ \\
Nodule 2 & $0.007^{\circ}$ \\
Nodule 3 & $0.021^{\circ}$ \\
Nodule 4 & $0.042^{\circ}$ \\
Nodule 5 & $0.011^{\circ}$ \\
Nodule 6 & $0.033^{\circ}$ \\
Nodule 7 & $0.041^{\circ}$ \\
Nodule 8 & $0.012^{\circ}$ \\
Nodule 9 & $0.014^{\circ}$ \\
Nodule 10 & $0.021^{\circ}$ \\
Nodule 11 & $0.013^{\circ}$ \\
Nodule 12 & $0.024^{\circ}$ \\
Nodule 13 & $0.023^{\circ}$ \\
Nodule 14 & $0.009^{\circ}$ \\
Nodule 15 & $0.004^{\circ}$ \\
Nodule 16 & $0.024^{\circ}$ \\
Nodule 17 & $0.024^{\circ}$ \\
Nodule 18 & $0.034^{\circ}$ \\
Nodule 19 & $0.029^{\circ}$ \\
Nodule 20 & $0.027^{\circ}$ \\
Nodule 21 & $0.010^{\circ}$ \\
Nodule 22 & $0.024^{\circ}$ \\
Nodule 23 & $0.020^{\circ}$ \\
Nodule 24 & $0.023^{\circ}$ \\
Nodule 25 & $0.022^{\circ}$ \\
Nodule 26 & $0.029^{\circ}$ \\
\hline
\end{tabular}




\begin{tabular}{|c|l|}
\hline Nodule 27 & $0.010^{\circ}$ \\
Nodule 28 & $0.022^{\circ}$ \\
Nodule 29 & $0.020^{\circ}$ \\
Nodule 30 & $0.016^{\circ}$ \\
Nodule 31 & $0.031^{\circ}$ \\
Nodule 32 & $0.020^{\circ}$ \\
Nodule 33 & $0.022^{\circ}$ \\
Nodule 34 & $0.011^{\circ}$ \\
Nodule 35 & $0.023^{\circ}$ \\
Nodule 36 & $0.022^{\circ}$ \\
Nodule 37 & $0.031^{\circ}$ \\
Nodule 38 & $0.025^{\circ}$ \\
Nodule 39 & $0.033^{\circ}$ \\
Nodule 40 & $0.012^{\circ}$ \\
Nodule 41 & $0.024^{\circ}$ \\
Nodule 42 & $0.025^{\circ}$ \\
Nodule 43 & $0.011^{\circ}$ \\
Nodule 44 & $0.026^{\circ}$ \\
Nodule 45 & $0.029^{\circ}$ \\
Nodule 46 & $0.030^{\circ}$ \\
Nodule 47 & $0.033^{\circ}$ \\
Nodule 48 & $0.043^{\circ}$ \\
Nodule 49 & $0.016^{\circ}$ \\
Nodule 50 & $0.024^{\circ}$ \\
Nodule 51 & $0.035^{\circ}$ \\
Nodule 52 & $0.045^{\circ}$ \\
\hline Average & $\mathbf{0 . 0 2 3}^{\circ}$ \\
\hline Maximum & $\mathbf{0 . 0 4 5}^{\circ}$ \\
\hline
\end{tabular}

Table A.1 Misorientation between the average orientations of 52 nodules resulting of two EBSD characterizations of the same region. This is indicative of the precision of the orientation measurements.

The lack of certainty of the rotation axis was then investigated with a special focus on the effect on the determination of the slip induced rotation axis. Rotations of $0.1^{\circ}, 0.2^{\circ}, 0.4^{\circ}$ and $1^{\circ}$ about [0001] of the hexagonal close packed lattice were applied to the orientations of the second set of orientation. This is equivalent to the rotations induced by the operation of prismatic slip. Finally the rotation of slip induced rotation axes was calculated between the first set of orientations and the second set that includes an applied rotation. These values are reported in table A.2. Any rotation magnitude leads to a minimum rotation magnitude of the B1, B2 or B3 axes higher than the maximum rotation magnitude of the $\mathrm{P}$ rotation axis. This reveals a proper determination of the [0001] rotation axis (based on the lowest rotation magnitude). Hence, the use of averaged orientations enables to avoid lack of certainty of the rotation axis issues for prediction of operating slip systems associated with rotation magnitudes as low as $0.1^{\circ}$. Increasing the number of slip systems (i.e. the number of axes) or reducing the number of individual EBSD measurements per grain would impair the confidence in prediction and the precision level.

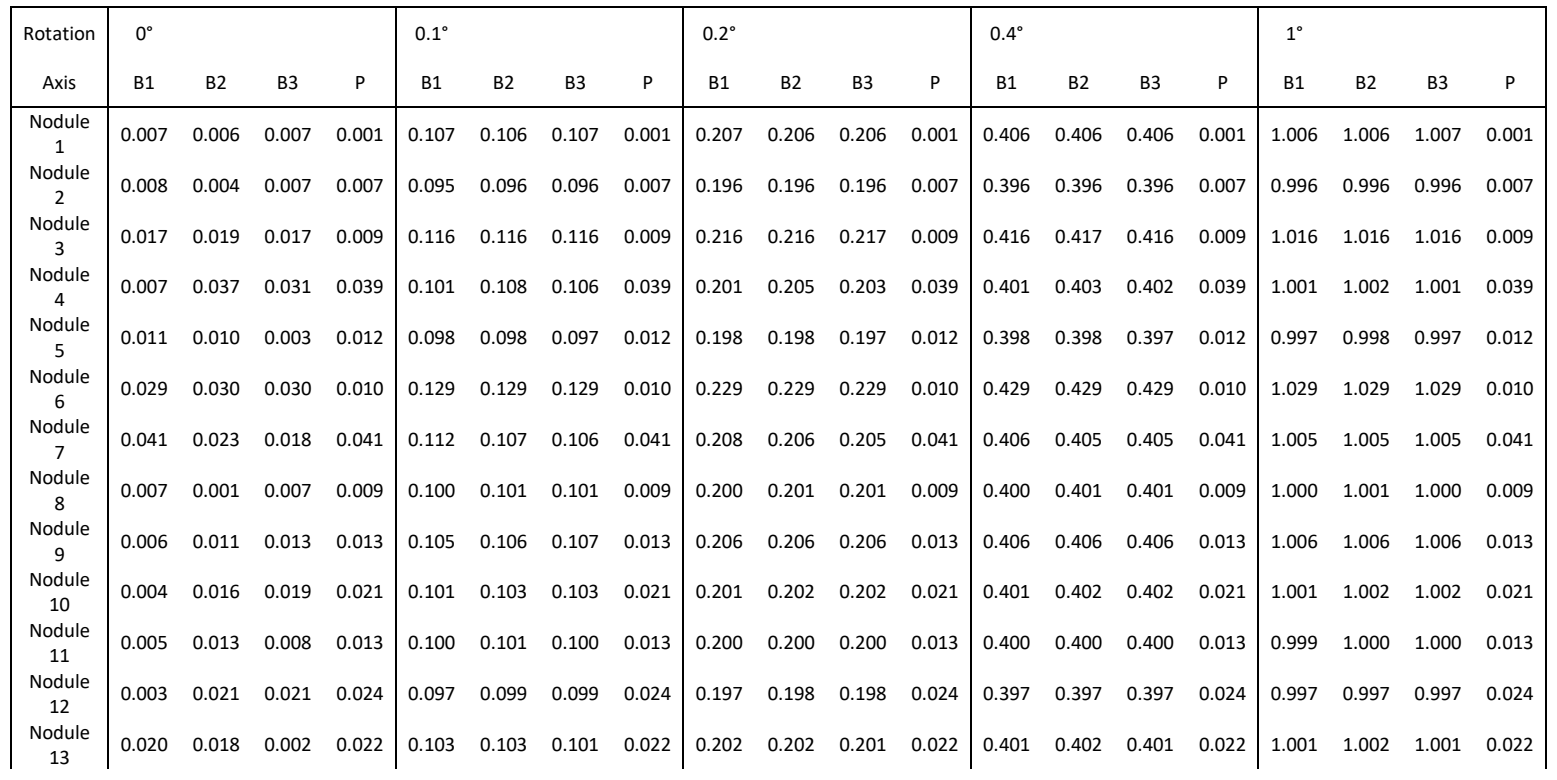




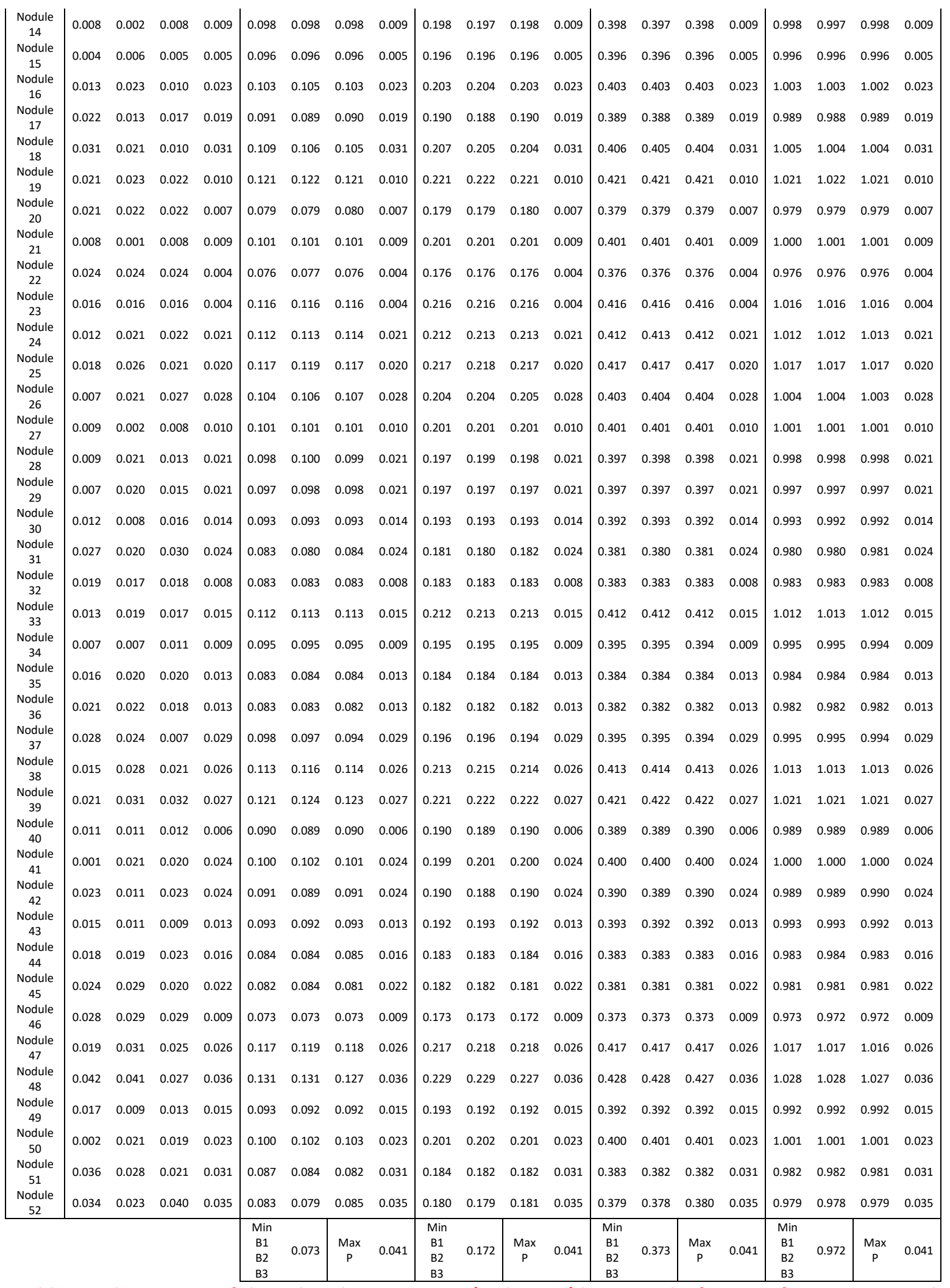

Table A.2 The rotation of slip induced rotation axes (in degrees) between the first set of orientations and the second set of orientation that includes an applied rotation for $\mathbf{5 2}$ nodules. For any rotation magnitude, no overlap was noticed between the minimum among B1, B2 and B3 axes rotation magnitudes and the $\mathrm{P}$ axis rotation magnitude, which indicates an accurate prediction of the operating deformation systems. 